\title{
Rapid Postnatal Expansion of Neural Networks Occurs in an Environment of Altered Neurovascular and Neurometabolic Coupling
}

\author{
Mariel G. Kozberg, Ying Ma, Mohammed A. Shaik, @Sharon H. Kim, and Elizabeth M. C. Hillman \\ Laboratory for Functional Optical Imaging, Departments of Biomedical Engineering and Radiology, Mortimer B. Zuckerman Mind Brain Behavior Institute \\ and Kavli Institute for Brain Science, Columbia University, New York, New York 10027
}

In the adult brain, increases in neural activity lead to increases in local blood flow. However, many prior measurements of functional hemodynamics in the neonatal brain, including functional magnetic resonance imaging (fMRI) in human infants, have noted altered and even inverted hemodynamic responses to stimuli. Here, we demonstrate that localized neural activity in early postnatal mice does not evoke blood flow increases as in the adult brain, and elucidate the neural and metabolic correlates of these altered functional hemodynamics as a function of developmental age. Using wide-field GCaMP imaging, the development of neural responses to somatosensory stimulus is visualized over the entire bilaterally exposed cortex. Neural responses are observed to progress from tightly localized, unilateral maps to bilateral responses as interhemispheric connectivity becomes established. Simultaneous hemodynamic imaging confirms that spatiotemporally coupled functional hyperemia is not present during these early stages of postnatal brain development, and develops gradually as cortical connectivity is established. Exploring the consequences of this lack of functional hyperemia, measurements of oxidative metabolism via flavoprotein fluorescence suggest that neural activity depletes local oxygen to below baseline levels at early developmental stages. Analysis of hemoglobin oxygenation dynamics at the same age confirms oxygen depletion for both stimulusevoked and resting-state neural activity. This state of unmet metabolic demand during neural network development poses new questions about the mechanisms of neurovascular development and its role in both normal and abnormal brain development. These results also provide important insights for the interpretation of fMRI studies of the developing brain.

Key words: flavoprotein fluorescence; fMRI; functional hyperemia; GCaMP imaging; neurovascular coupling; oxygen consumption; postnatal neural development

\section{Significance Statement}

This work demonstrates that the postnatal development of neuronal connectivity is accompanied by development of the mechanisms that regulate local blood flow in response to neural activity. Novel in vivo imaging reveals that, in the developing mouse brain, strong and localized GCaMP neural responses to stimulus fail to evoke local blood flow increases, leading to a state in which oxygen levels become locally depleted. These results demonstrate that the development of cortical connectivity occurs in an environment of altered energy availability that itself may play a role in shaping normal brain development. These findings have important implications for understanding the pathophysiology of abnormal developmental trajectories, and for the interpretation of functional magnetic resonance imaging data acquired in the developing brain.

\section{Introduction}

The tight coupling between neural activity and local blood flow in the brain is the foundation of functional magnetic resonance

Received June 4, 2015; revised April 23, 2016; accepted May 10, 2016.

Author contributions: M.G.K. and E.M.C.H. designed research; M.G.K., Y.M., M.A.S., S.H.K., and E.M.C.H. performed research; M.G.K., Y.M., M.A.S., and E.M.C.H. analyzed data; M.G.K. and E.M.C.H. wrote the paper.

This work was supported by National Institutes of Health grants (1R01NS063226, 1R01NS076628 and R21NS053684, to E.M.C.H.; T32 GM07367 MSTP and F31 NS084538, to M.G.K.; F30 HL128023 to M.A.S.), a National Science Foundation grant (Faculty Early Career Development 0954796, to E.M.C.H.), the Human Frontier Science Program, and the Kavli Foundation. We thank Professors Costantino ladecola, Randy Bruno, Franck Polleux, Vincent imaging (fMRI; Logothetis et al., 2001). In the normal adult brain, neural activity drives local increases in blood flow which

Ferrera, and Aniruddha Das for helpful discussions; Peter Canoll and his laboratory for histology assistance; Laboratory for Functional Optical Imaging members, particularly Brenda Chen, Matthew Bouchard, David Thibodeaux, and Jacob Portes, for assistance with experiments, technology development, and helpful discussions.

The authors declare no competing financial interests.

Correspondence should be addressed to either of the following: Mariel G. Kozberg or Elizabeth M. C. Hillman at the above address. E-mail:mkozberg@gmail.com or eh2245@columbia.edu.

DOI:10.1523/JNEUROSCI.2363-15.2016

Copyright $\odot 2016$ the authors $\quad 0270-6474 / 16 / 366704-14 \$ 15.00 / 0$ 
overoxygenate the region, decreasing the local concentration of paramagnetic deoxyhemoglobin and generating the "positive" blood oxygen level-dependent (BOLD) fMRI signal interpreted as functional activation (Heeger and Ress, 2002; Hillman, 2014). Until recently, it has been generally assumed that neurovascular coupling is fully developed in the newborn brain and that any developmental differences in fMRI responses are directly reporting differences in underlying neural activity.

However, neurons and vasculature in the brain are known to develop significantly postnatally both morphologically and functionally. Substantial angiogenesis, as well as vascular pruning (Norman, 1986), occurs postnatally, with recent results suggesting that microvascular development is directly influenced by levels of neural activity (Lacoste et al., 2014; Whiteus et al., 2014). Neural connectivity increases rapidly during the same period. This connectivity includes the establishment of transcallosal axonal projections (Wang et al., 2007; Lewis et al., 2013) and synaptogenesis throughout the cortex (Cohen-Cory, 2002), followed by circuit refinement and synaptic pruning (Huttenlocher et al., 1982).

This state of ongoing neurovascular codevelopment may lead to altered functional coupling, as supported by prior functional imaging studies of the developing brain. These studies, using fMRI and near infrared spectroscopy in both humans (Born et al., 1996; Meek et al., 1998; Anderson et al., 2001) and rodent models (Kozberg et al., 2013; Zehendner et al., 2013), have noted different and even inverted BOLD responses to stimulation. However, because none of these studies has assessed spatiotemporal neural activity in parallel with hemodynamic measurements, it remains unknown whether altered BOLD signals are a direct reflection of neural circuit development, vascular development, and/or a difference in neurovascular coupling itself.

This study, using wide-field simultaneous imaging of neuronal GCaMP fluorescence and oxygenation-dependent hemoglobin absorption, examines the spatiotemporal dynamics of both neural and hemodynamic responses to somatosensory stimulation in mice. Our results confirm that adult-like hemodynamic responses do not occur in the newborn brain despite the presence of robust localized neural activity. Neural responses were found to bilateralize and expand during this postnatal period as networks are established. To discover how this uncoupled neurovascular state could sustain the energetic needs of the developing brain, flavin adenine dinucleotide (FAD) fluorescence was imaged as a marker of oxidative metabolism. Additional analysis of hemoglobin oxygenation in both stimulus-evoked and resting-state conditions confirmed that oxygen is depleted below baseline levels following neural events in the developing brain.

These findings support the hypothesis that anomalous fMRI responses observed in the neonatal brain are the direct result of altered neurovascular coupling. Cortical vascular dynamics were confirmed to be initially spatiotemporally uncoupled from neural activity, with neurovascular coupling maturing throughout the postnatal establishment of intrahemispheric and interhemispheric neural circuits. The lack of early neurovascular coupling is demonstrated to result in a unique metabolic environment in the developing brain in which neural events drive local oxygen depletion. These underexplored features of the developing brain could provide new insights into the mechanisms of normal and abnormal brain development.

\section{Materials and Methods}

This study used simultaneous wide-field optical imaging of both neural activity and blood oxyhemoglobin ( $\mathrm{HbO}$ ) and deoxyhemoglobin ( $\mathrm{HbR})$ dynamics, as well as laser speckle-flow imaging over most of the bilaterally exposed neocortex in Thy1-GCaMP3/6f mice (Bouchard et al., 2009; Boas and Dunn, 2010; Chen et al., 2011) from postnatal day (P) 7 through adulthood. Simultaneous hemodynamic and FAD fluorescence imaging data were acquired using similar methods in wild-type mice.

\section{Animal preparation}

B6; CBA-Tg(Thy1-GCaMP3)6Gfng/J (http://jaxmice.jax.org/strain/ 017893.html) hemizygotes and wild-type C57BL/6J (http://jaxmice.jax. org/strain/000664.html) mice of either sex were imaged for GCaMP and FAD experiments respectively. Experiments in Figure 6 were performed using C57BL/6J-Tg(Thy1-GCaMP6f)GP5.17Dkim/J (https://www.jax. org/strain/025393) hemizygotes.

Before surgery, mice were anesthetized with $1.5 \mathrm{mg} / \mathrm{kg}$ urethane administered intraperitoneally. Glycopyrrolate $(0.5 \mathrm{mg} / \mathrm{kg})$ was also administered intraperitoneally. For experiments shown in Figure 6, mice were anesthetized for surgery with $2.5 \%$ isoflurane in a 3:1 air/oxygen mix. Core body temperature was maintained at $37^{\circ} \mathrm{C}$ by a homeothermic heating system (Stoelting). Heart rate and arterial oxygen saturation were monitored continuously throughout surgery and imaging using a rodent pulse oximeter (Kent Scientific MouseSTAT). Each mouse was placed in a custom-designed stereotaxic frame and the skull between bregma and lambda cranial sutures was exposed and thinned to translucency using a dental drill (minimal drilling was required for mouse pups). To prevent motion artifacts during imaging, a glass coverslip was sealed to the skull and the stereotaxic frame using dental acrylic (Henry Schein), with a drop of $1.5 \%$ agarose in artificial CSF between the skull and the coverslip.

Each stimulus imaging trial consisted of recording for $6 \mathrm{~s}$ prestimulation, $4 \mathrm{~s}$ stimulation, and $30 \mathrm{~s}$ poststimulation. For electrical stimulation, bipolar stimulation was provided via electrodes ( $30 \mathrm{ga}$ ) inserted into the lateral and medial sides of the hindpaw and connected to stimulus isolation unit (A360, WPI). Stimuli were $0.1-0.5 \mathrm{~mA}, 3 \mathrm{~ms}$ pulses delivered to the hindpaw at $3 \mathrm{~Hz}$ for $4 \mathrm{~s}$. Stimulus amplitudes were adjusted for each mouse to the lowest amplitude that resulted in a hindpaw twitch and were on average slightly lower in the younger age groups. Tactile hindpaw stimuli consisted of inserting the hindpaw into a plastic pipette set to vibrate continuously at $25 \mathrm{~Hz}$ for a $4 \mathrm{~s}$ stimulation period. For tactile whisker stimulation, a stepper motor attached to a rectangular bar was used to stimulate all whiskers on one side in an up-down (i.e., ventraldorsal) direction continuously at $25 \mathrm{~Hz}$.

Urethane-anesthetized mice were imaged under continuing urethane anesthesia, while imaging of the mice shown in Figure 6 was performed either under light isoflurane anesthesia (1-2\%) or in unanesthetized conditions. Resting-state imaging trials (under urethane) consisted of $180 \mathrm{~s}$ of imaging time. Each mouse was imaged for $\leq 4 \mathrm{~h}$. Data were acquired in P7-P8, P10-P13, and adult (P70+) age groups.

GCaMP expression was confirmed in layers $2 / 3$ and 5 in all age groups (Fig. 1). All animal procedures were reviewed and approved by the Columbia University Institutional Animal Care and Use Committee.

\section{Multispectral hemodynamic and fluorescence imaging}

Imaging was performed using a custom wide-field optical mapping system for fluorescence and multispectral optical intrinsic signal imaging. The system composed of a Dalsa 1M60 CCD camera (Andor iXon for data shown in Figs. 2, Fig. 5, Fig. 6) acquiring synchronously with strobing, coaligned light emitting diodes (LEDs; Bouchard et al., 2009; Chen et al., 2011). In both GCaMP3/6 and FAD experiments, blue light was used to excite fluorescence, while green and red light illumination provided diffuse reflectance measurements to permit calculation of $\mathrm{HbO}$ and $\mathrm{HbR}$ concentrations as described below. Both experiments used the same green and red LEDs (Thorlabs M530L2 with an Edmund Optics 67-031, $535 / 43 \mathrm{~nm}$ filter, and Thorlabs M625L2 respectively), and a Semrock FF01-496/LP-25 long-pass filter in front of the camera to reject blue excitation light. GCaMP experiments used a Thorlabs M490L2 blue LED with a Semrock BrightLine 460-60 filter for excitation, and triwavelength data were collected at 45 frames per second (fps), equivalent to $15 \mathrm{fps}$ per wavelength, with a $5 \mathrm{~ms}$ exposure time and $128 \times 128$ pixel resolution. FAD experiments used a Thorlabs 470L2 LED with a Semrock BrightLine 460-60 filter for excitation, and tri-wavelength data were col- 

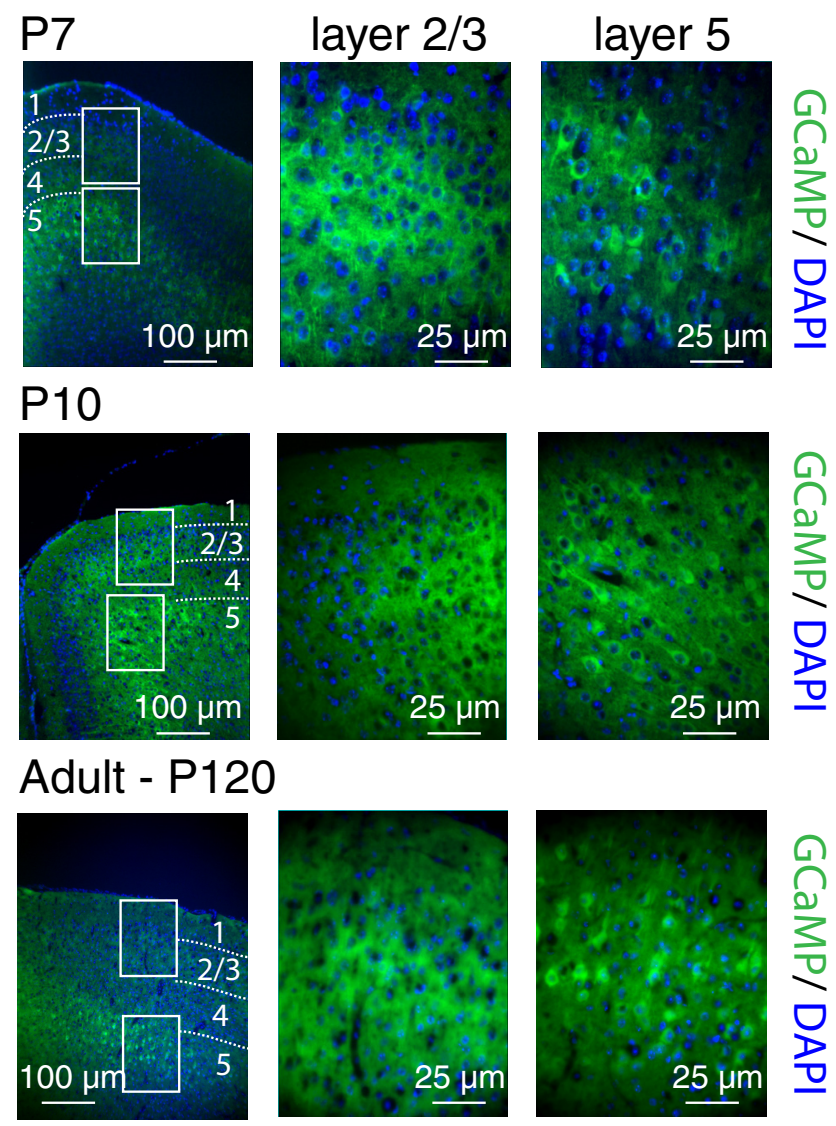

Figure 1. GCaMP expression is observed in neurons of layers $2 / 3$ and 5 of Thy $1-G C a M P 3$ mice in all three age groups. Images of coronal slices $(10 \mu \mathrm{m})$ stained with DAPI taken from P7, P10, and adult (P120) mice. White boxes on images on left indicate regions magnified in images on right.

lected at $30 \mathrm{fps}$, equivalent to $10 \mathrm{fps}$ per wavelength, with a slower $25 \mathrm{~ms}$ exposure time and $128 \times 128$ pixel resolution to compensate for the much lower fluorescence levels of FAD compared with GCaMP. For simultaneous hemodynamic and laser speckle imaging, laser diode illumination at $808 \mathrm{~nm}$ was interlaced with 530 and $625 \mathrm{~nm}$ LED illumination using a $10 \mathrm{~ms}$ exposure time.

Given the overlapping spectra of FAD and GCaMP, control experiments were performed using the GCaMP imaging parameters described above to image wild-type mice. Contributions of FAD fluorescence to the GCaMP response are estimated to be insignificant at $\sim 4,4$, and $11 \%$ in P7-P8, P10-P13, and adult animals respectively.

\section{Data processing}

Hemodynamic data. Green and red reflectance data were temporally lowpass filtered at $3 \mathrm{~Hz}$, and divided by respective prestimulus reflectance values. Based on the different absorption spectra of $\mathrm{HbO}$ and $\mathrm{HbR}$ at visible wavelengths, these data were then converted to movies of $\Delta[\mathrm{HbO}]$ and $\Delta[\mathrm{HbR}]$ using the modified Beer-Lambert law with wavelengthdependent path length factors derived from Monte Carlo modeling (Hillman et al., 2007; Sakaguchi et al., 2007; Bouchard et al., 2009). The resulting images represent a superficially weighted sum of signal from the cortex, extending 300-500 $\mu \mathrm{m}$ below the surface. The use of $535 \mathrm{~nm}$ (green) as one of the reflectance wavelengths provides an isosbestic measurement that is insensitive to hemoglobin oxygenation, providing a useful reference measure of tissue blood volume ( $\mathrm{HbT}$ ), independently of spectroscopic analysis. Laser speckle-flow data were analyzed using temporal speckle contrast as previously described (Boas and Dunn, 2010).

Fluorescence data absorption correction (GCaMP and FAD). Since both GCaMP and FAD excite at blue wavelengths and emit at green wavelengths, the strong absorption of hemoglobin at these wavelengths can affect detected fluorescence intensity. It is necessary to correct for this cross-talk effect when large changes in cortical blood volume and oxygenation are occurring at the same time as FAD or GCaMP dynamics. Mathematically, detected fluorescence intensity $F_{M}$ will equal the true fluorescence $F$ scaled by a time-varying multiplicative factor as follows (Eq. 1):

$$
F_{M}(t)=F(t) e^{-\left(\Delta \mu_{\mathrm{a} 1}(t) x_{1}+\Delta \mu_{\mathrm{a} 2}(t) x_{2}\right)}
$$

where $\Delta \mu_{\mathrm{a} 1}(t)$ and $\Delta \mu_{\mathrm{a} 2}(t)$ are time-varying changes in absorption coefficient at the fluorophore excitation and emission wavelengths respectively, and $x_{1}$ and $x_{2}$ are the corresponding approximate path lengths that excitation and emission light traveled to and from the fluorophore respectively. Although concurrently recorded [HbT], [HbO], and [HbR] dynamics can be used to estimate $\Delta \mu_{\mathrm{a} 1}(t)$ and $\Delta \mu_{\mathrm{a} 2}(t), x_{1}$ and $x_{2}$ are not equivalent for fluorescence and reflectance, limiting accuracy. For a simple stimulus, an alternative approach is to separate these two spatiotemporally uncorrelated components by performing principal component analysis (PCA) on the logarithm of the measured fluorescence, where $\log \left[F_{M}(t)\right]$ becomes a linear sum of $\log [F(t)]-\left[\Delta \mu_{\mathrm{a} 1}(t) \mathrm{x}_{1}+\Delta \mu_{\mathrm{a} 2}(t) \mathrm{x}_{2}\right]$. The results of this analysis were found to produce cleanly separated spatiotemporal components resembling the GCaMP or FAD response, and maps and time courses that were confirmed to resemble simultaneously acquired hemodynamics. Removal of this primary hemodynamic response component yielded absorption-corrected $\Delta F / F$ values that were used for both the FAD and GCaMP time courses shown.

Note that since hemodynamics primarily affect the later parts of the response time course, to avoid confounds related to this correction, raw, uncorrected data were used for all functional maps shown, as well as for parameter comparisons in Figures 4 and 6. Because of the two phases of FAD fluorescence extend into the time period of maximum hemodynamic activity, PCA-corrected outputs were used for parameter comparisons in Figure 8.

Hemodynamic global-signal subtraction. Global hemodynamic responses were observed in P7-P8 and P10-P13 age groups. For Figure 9, to remove this global signal and detect underlying local oxygenation changes, PCA was performed on both $\Delta[\mathrm{HbO}]$ and $\Delta[\mathrm{HbR}]$ image sequences. The principal component accounting for most of the variance in the data was found to accurately depict the perceptible global response in the data. Subtracting this global component from the original image sequences revealed finer-scale oxygenation and hyperemia dynamics consistent across animals. The time courses and maps shown in Figure 9 were generated from these global-subtracted image sequences.

Resting-state data analysis. Spontaneous GCaMP neural events were observed during "resting state" runs in which no stimulus was delivered. To determine the average neurovascular response to these spontaneous neural events, event times $t_{N}$ were defined as points with local maxima in the GCaMP fluorescence maximum intensity projection time course (generally $>3 \%$ over background after bandpass filtering to smooth and remove absorption contamination). To remove large, global trends in the hemodynamic recordings of the two younger age groups, PCA was performed and the first, largest principal component subtracted to yield corrected $\Delta\left[\mathrm{HbO}_{\mathrm{c}}\right]$ and $\Delta\left[\mathrm{HbR}_{\mathrm{c}}\right]$ data. For each neural event $t_{N}$, its spatial location $r_{N}$ was determined, and then corresponding data blocks of $\Delta\left[\mathrm{HbO}_{\mathrm{c}}\right]\left(r_{N}\right)$ and $\Delta\left[\mathrm{HbR}_{\mathrm{c}}\right]\left(r_{N}\right)$ spanning $5 \mathrm{~s}$ before and $15 \mathrm{~s}$ after the event were extracted from the same region. $\Delta\left[\mathrm{HbO}_{\mathrm{c}}\right]$ and $\Delta\left[\mathrm{HbR}_{\mathrm{c}}\right]$ time courses were averaged across all the events found within each animal and then the time courses of animals from the same age group were weightedaveraged based on the number of events detected for each animal.

\section{Statistical analysis}

All stimulus trials were averaged together within each animal and subsequently averaged within each age group to generate the time courses and standard errors of the means (SEMs) shown. Single-mouse averages were also used to generate functional maps, movies, and onset-time maps; to perform PCA; and to calculate parameter averages and $p$-values. The number of animals used in each average are noted in each figure caption. Student's $t$ tests were used for all parameter comparisons. 
A
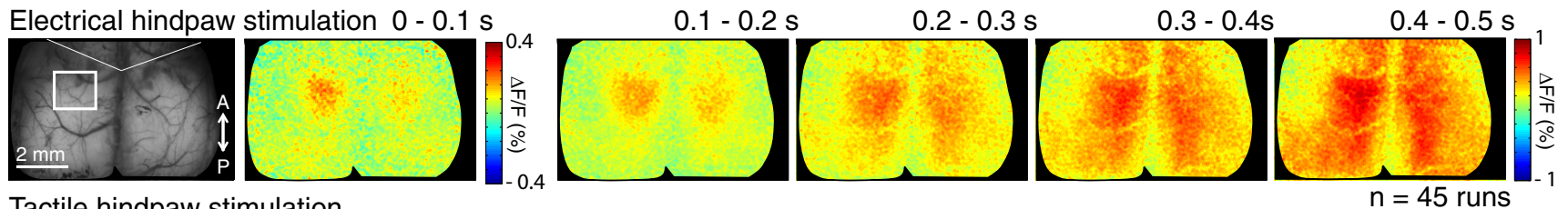

Tactile hindpaw stimulation
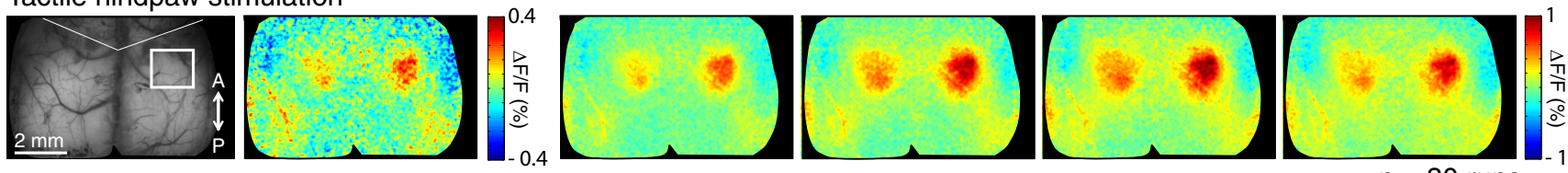

Tactile whisker stimulation
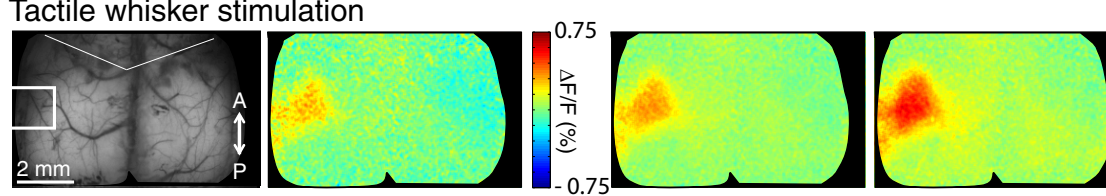

B

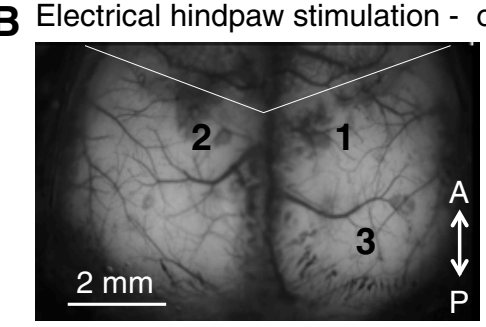

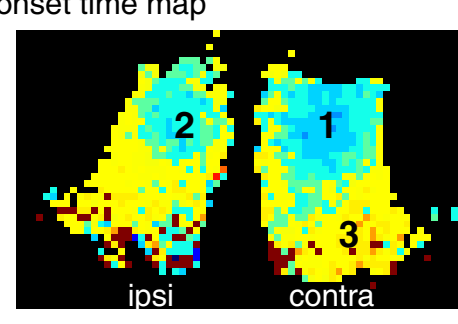

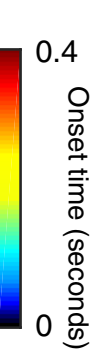

C $\stackrel{0}{\circ}$
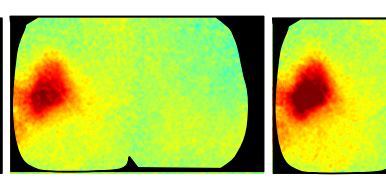

$\mathrm{n}=30$ runs

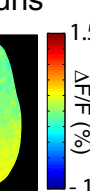

$\mathrm{n}=45$ runs

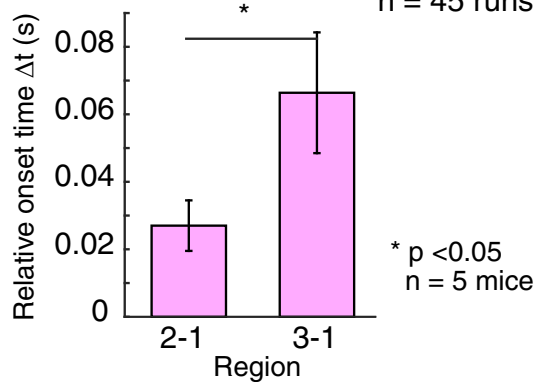

Figure 2. Spatiotemporal analysis of GCaMP fluorescence responses in the adult brain to three types of somatosensory stimulation. $\boldsymbol{A}$, Left, Grayscale images of a representative adult Thy1-GCaMP3 mouse. Bregma suture lines are marked with white lines; boxes represent expected regions of neural responses based on stimulation type and side. Right, Time sequences of GCaMP responses during the initial stimulation period for three different types of unilateral, $4 \mathrm{~s}$ stimuli (note, electrical and tactile hindpaw stimulation were performed on the right and left hindpaws respectively to permit randomized collection of all data in the same animal). $\boldsymbol{B}$, Analysis of neural response onset times. Onset time calculated as the time of the peak of the first derivative of the time course of each pixel. Left, Grayscale image from representative GCaMP3 mouse. Right, Map depicting the onset timing of the GCaMP response for each pixel that reached $\geq 40 \%$ of the peak response. Numbers indicate the sequence of propagations of the neural response: 1, contralateral hindpaw region; 2, ipsilateral hindpaw region; 3, close to the contralateral visual cortex. C, Relative onset time comparing regions 2 and 3 to the origin of the response (region 1: hindpaw region of the contralateral somatosensory cortex and region of peak neural response).

\section{Results}

Wide-field GCaMP fluorescence as a marker of local neural activity

Increases in GCaMP fluorescence were consistently observed in response to electrical and tactile hindpaw stimulation and tactile whisker stimulation, with spatiotemporal dynamics varying based on animal age (Fig. 3 ) and stimulus type. To capture the dynamics of these fluorescence responses in adult mice and confirm that they are representative of underlying neural activity, experiments were performed at high frame rates ( 45 fps per wavelength) using an Andor Zyla camera. In adult GCaMP3/6 mice, neural responses to unilateral hindpaw or whisker stimulation were initially localized to the contralateral hindpaw or whisker region of the somatosensory cortex respectively before spreading to other cortical regions (Fig. 2A). Whisker responses were primarily observed to be unilateral. However, both tactile and electrical unilateral hindpaw stimulation resulted in bilateral neural responses. The neural response to electrical hindpaw stimulus was found to spread more broadly over the cortex at later time points than tactile stimulus in the adult brain. These spatiotemporal patterns were observed consistently across all adult mice imaged. Electrical hindpaw stimulation was used for the majority of experiments across age groups because it allowed precise titration of the stimulus intensity. However, results in younger age groups are compared with tactile hindpaw stimulation in Figure 6.
High-speed imaging of GCaMP fluorescence across the brain enables calculation of the onset time of responses (calculated as the peak of the first derivative of the time course of specified regions). The onset-time map in Figure $2 B$ for a representative GCaMP3 adult shows that during electrical hindpaw stimulation in the adult, neural activity is first observed in the contralateral hindpaw region of the somatosensory cortex before spreading to the ipsilateral hindpaw region and then spreading out across the cortex (shown for pixels with $>40 \%$ of the peak neural response). Figure $2 C$ confirms this pattern across mice, showing the average onset-time difference between the initial contralateral hindpaw neural response (1), and the response observed in ipsilateral hindpaw (2) and adjacent cortex (3).

While bilateral and spreading neural responses to a unilateral somatosensory stimulus may seem surprising, this distribution of neural responses in adult animals is consistent with prior voltagesensitive dye studies in adult rodents (Ferezou et al., 2007; Mohajerani et al., 2010), as well as fMRI studies in rodents and humans (Mall et al., 2005; Colonnese et al., 2008).

\section{Neural circuit development}

Using the same methodology as above, Figure $3 A$ charts the observed progression of cortical neural responses to unilateral electrical hindpaw stimulus in mice as a function of postnatal age. In the youngest animals (P7-P8), neural GCaMP responses are strongly localized to a discrete unilateral location corresponding 
A
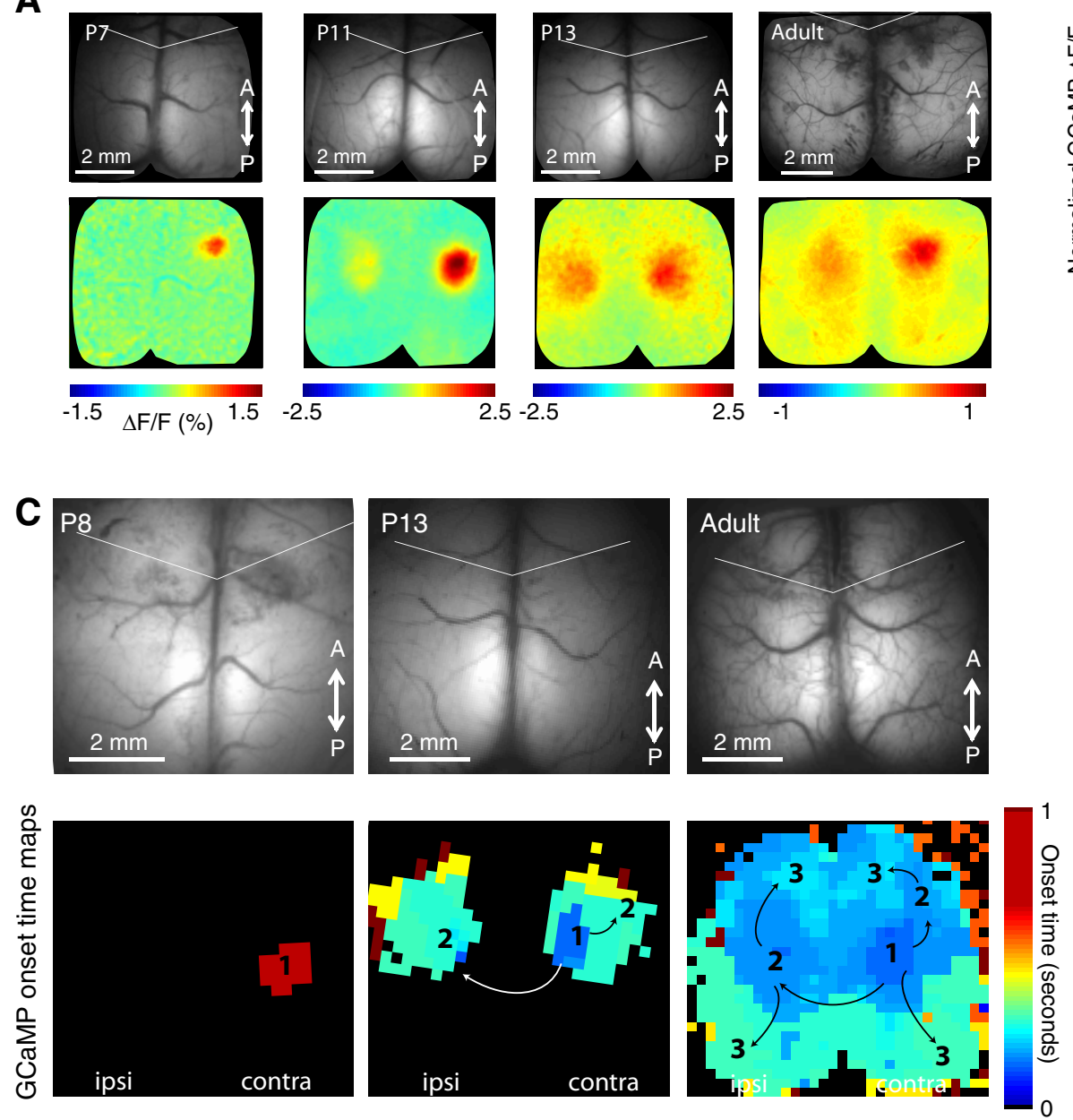
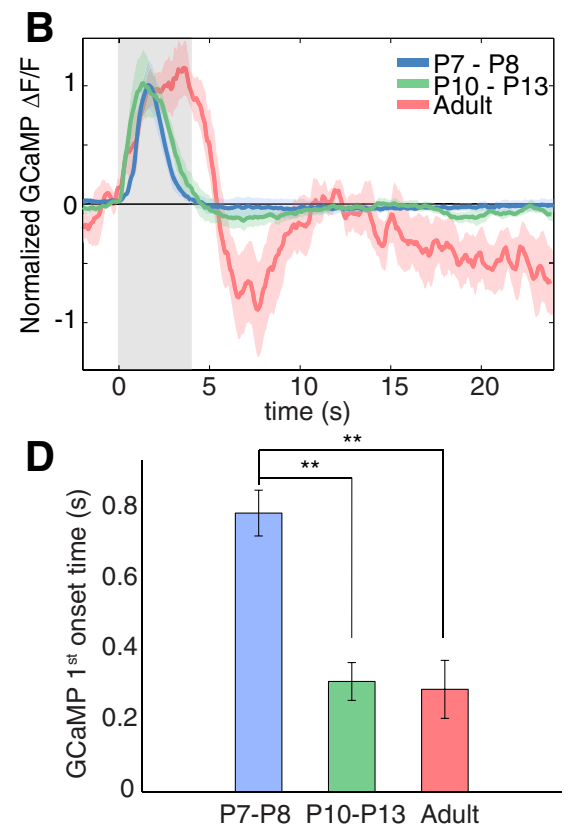

** $p<0.005$

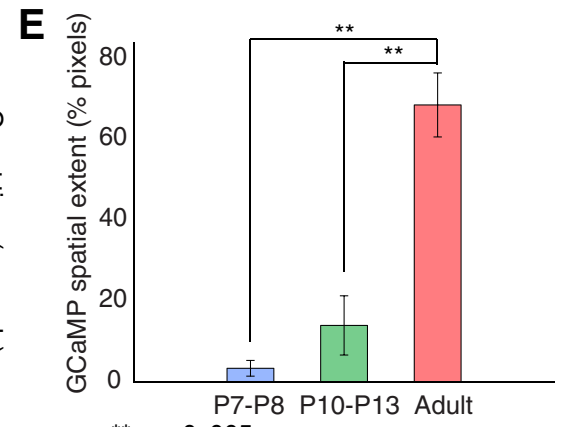

** $p<0.005$

Figure 3. Spatiotemporal progression of neural network development. $A$, The developing neural response to unilateral hindpaw stimulation. Top, Grayscale images of representative P7, P11, P13, and adult mice. Bregma suture lines are marked with white lines. Bottom, GCaMP response maps comparing $0-2$ s poststimulus onset to baseline. $\boldsymbol{B}$, Normalized GCaMP responses to $4 \mathrm{~s}$ hindpaw stimulation for P7-P8, P10-P13, and adult age groups ( $n=5,6,6$ mice) extracted from the contralateral hindpaw region of the somatosensory cortex. Error bounds show SEM. C, Analysis of neural response onset times. Top, Grayscale images of representative animals. Bottom, Maps depicting the onset timing of the GCaMP response for each pixel that reached $\geq 50 \%$ of the peak response. Numbers and arrows indicate the sequence and directions of propagations of the neural response, all indicating initial onset in the hindpaw region of the somatosensory cortex contralateral to stimulation. D, GCaMP response onset time (measured as the peak of the first derivative of the time courses) decreases significantly between the P7-P8 and P10 -P13 age groups $(p<0.005$, Student's $t$ test). $\boldsymbol{E}$, Spatial spread of the neural response increases with age $(p<0.005$ comparing the P7-P8 and P10-P13 age groups to the adult), calculated as the percentage of pixels that reach $\geq 50 \%$ of the peak response pixel. All error bounds and bars show SEM.

to the hindpaw region of the somatosensory cortex contralateral to the stimulated paw. The group-averaged time course of the P7-P8 neural GCaMP response shows a delayed onset and shorter duration than the adult response (Fig. $3 B$ ). In the older P10-P13 animals, the neural response is more bilateral, although still well localized to the hindpaw regions of both the contralateral and ipsilateral somatosensory cortices. The response onset time for this group was faster than that of the younger age group, but neural responses were shorter in overall duration than the period of stimulus delivery ( $4 \mathrm{~s}$ ). In adults, the neural response is more widely distributed across the cortex bilaterally (Figs. 2, 3) and is sustained for the duration of the $4 \mathrm{~s}$ stimulation.

Figure $3 C$ displays onset-time maps for the GCaMP response in representative animals in each age group. In all cases, the first response is seen in the hindpaw region of the somatosensory cortex contralateral to the stimulated paw, as expected. However, at $\mathrm{P} 7-\mathrm{P} 8$, the neural response begins significantly later (averaged across mice in Fig. 3D), which is consistent with previously reported delays in the neural response of $\mathrm{P} 7$ mice attributed to lower levels of myelination (Zehendner et al., 2013). The P7-P8 response also remains spatially restricted to the contralateral hindpaw region (averaged across mice as the spatial extent of pixels exceeding $50 \%$ of the peak response in Fig. $3 E$ ). This limited response distribution is similar to the lateralized somatosensory-evoked neural activity previously observed in early postnatal mice and rats (Marcano-Reik and Blumberg, 2008; Quairiaux et al., 2011; McVea et al., 2012). In the P10-P13 age group, the response initiates in the contralateral hindpaw region and then spreads quickly to the ipsilateral side. The response then spreads further, but is limited to the somatosensory and motor cortices. The adult onset-time map, consistent with Figure $2 B$, reveals a rapid onset of the neural response in the contralateral hindpaw region, which then spreads quickly to the ipsilateral side and then to the motor cortex before extending to other brain regions, encompassing the retrosplenial and visual cortices (Fig. 3E). These patterns of developing neural activity are consistent with the development of interhemispheric connectivity observed histologically (Wang et al., 2007; Lewis et al., 2013). 
A
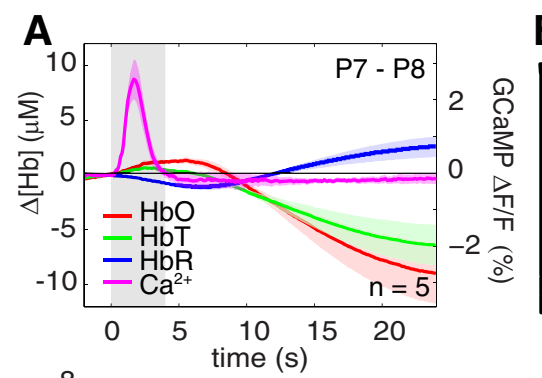

B
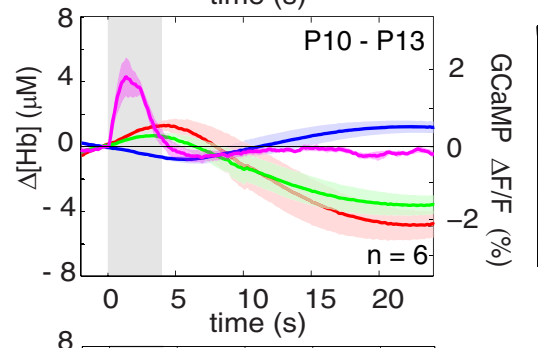
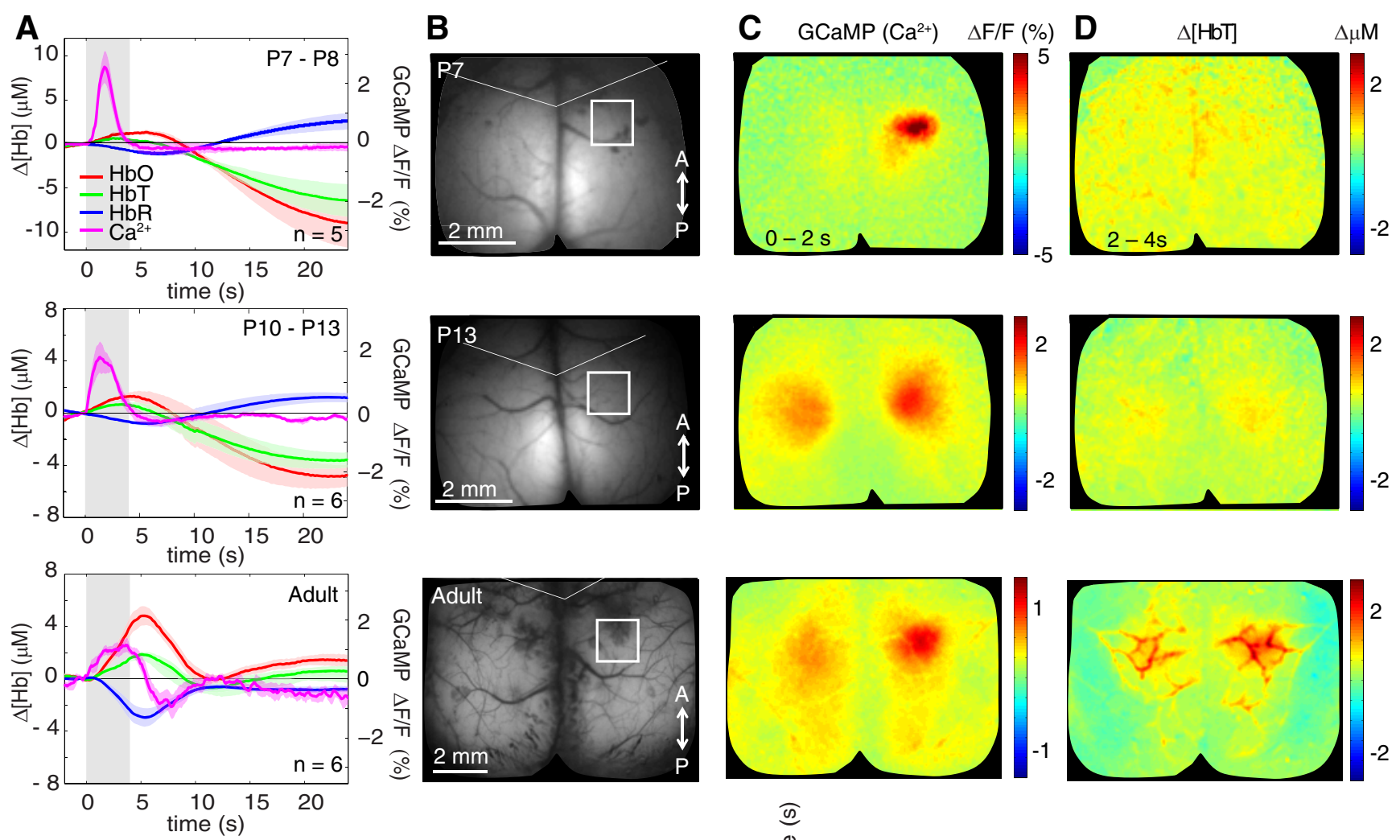

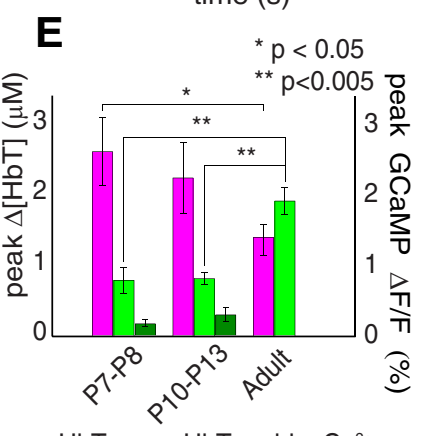

$\because \mathrm{HbT}$ raw $=\mathrm{HbT}$ resid $=\mathrm{Ca}^{2+}$

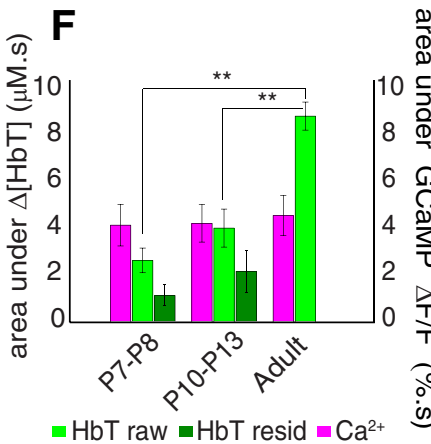

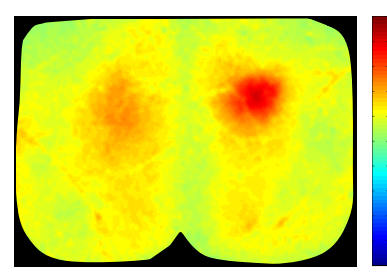

(5)

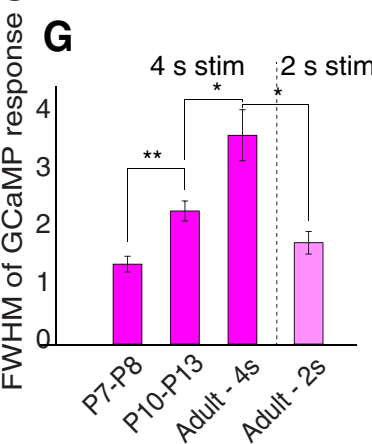

H

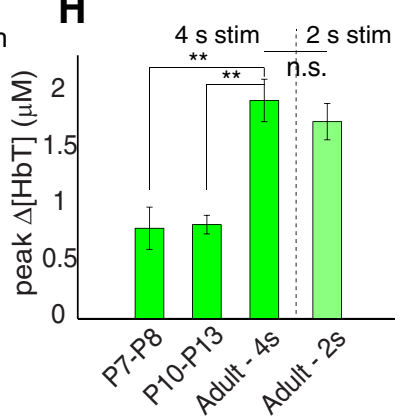

Figure 4. Neural responses are not accompanied by functional hyperemia in the neonatal mouse brain. $A$, Averaged hemodynamic and GCaMP time courses from the somatosensory cortex of Thy1-GCaMP3 mice in P7-P8, P10-P13, and adult age groups ( $n=5,6,6$ mice respectively). Hb0, HbR, total hemoglobin (HbT), and GCaMP fluorescence ( $\left(\mathrm{a}^{2+}\right)$ time courses were extracted from the region of maximal neural responses to unilateral hindpaw stimulation in each mouse ( $\boldsymbol{B}$, white boxes). Error bounds show SEM. $\boldsymbol{B}$, Grayscale images of representative mice from each age group. Bregma suture lines are marked with white lines. C, GCaMP response maps for the same mice comparing the time period $0-2 \mathrm{~s}$ poststimulus onset to baseline. $\boldsymbol{D}, \Delta[\mathrm{HbT}]$ functional maps for the same mice comparing the time period $2-4$ s poststimulus onset to baseline (averages of $n=9,12,51$ trials respectively). $\boldsymbol{E}, \boldsymbol{F}$, Peak amplitude $(\boldsymbol{E})$ and area under the curve $(\boldsymbol{F})$ of $\mathrm{GCaMP}$ and $\Delta[\mathrm{HbT}]$ responses (for both the raw $[\mathrm{HbT}]$ signal and residual responses after subtraction of the global $\Delta[\mathrm{HbT}]$ component; $n=5,6,6$ mice respectively). Error bars show SEM, $p$ values use Student's $t$ test. Responses were extracted from the region of peak GCaMP response. $\mathbf{G}, \boldsymbol{H}$, Full-width half-maximum (FWHM) of GCaMP responses $(\boldsymbol{G})$ and peak values of (raw) $\Delta[\mathrm{HbT}]$ responses $(\boldsymbol{H})$ to a $4 \mathrm{~s}$ hindpaw stimulus across age groups, compared with FWHM of adult GCaMP response to a $2 s$ stimulus ( $n=5,6,6,4$ mice respectively).

\section{Local hyperemia is absent despite robust neural activity in P7 mice}

Hemodynamic responses were recorded simultaneously in all GCaMP mice. Figure 4 shows the parallel evolution of cortical neural and hemodynamic responses to unilateral hindpaw stimulus as a function of postnatal age. These hemodynamic responses exhibit a very different spatiotemporal pattern from the developing neural responses shown above: in the P7-P8 age group, little to no localized increases in [HbT] (functional hyperemia) are observed (Fig. $4 A, E, F, H$ ). In the intermediate P10P13 age group, some low-amplitude localized functional hyperemia can be discerned in both the contralateral and ipsilateral hindpaw regions, consistent with the locations of neural activity, although with $\Delta[\mathrm{HbT}]$ amplitudes significantly lower than in the adult group $(p<0.005)$. The adult $\Delta[\mathrm{HbT}]$ response is strong and matched spatially to the GCaMP-responding regions. Note that we focus here on mapping changes in cortical [HbT], the local tissue concentration of hemoglobin, as a marker for the active modulation of vessel diameter and thus active neurovascular coupling driving functional hyperemia. Comparing the peaks and areas under the curve of GCaMP and [HbT] responses across the age groups (Fig. $4 E, F$ ), neither shows a matching trend between neural and hemodynamic responses.

Since neural responses to stimulus were markedly shorter in duration in the younger two age groups compared with adults (Fig. 3B), an additional experiment was performed to determine whether a shorter duration neural response could account for the observed differences in functional hyperemia. In this case, adult 
A

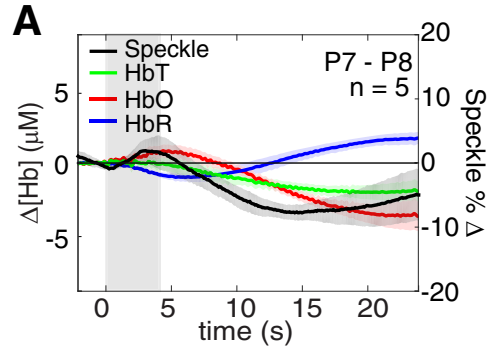

B

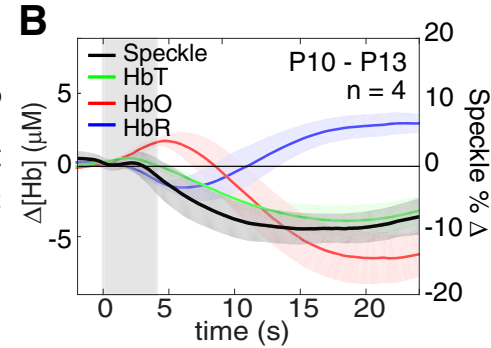

C

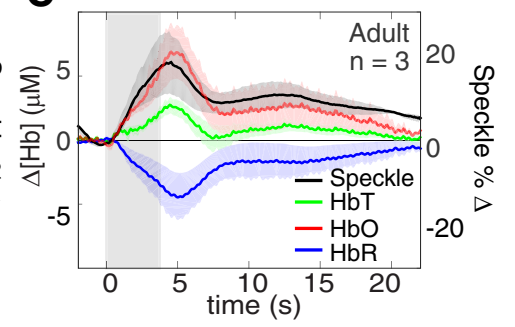

Figure 5. Local cerebral blood flow does not increase in response to stimulation in the neonatal mouse brain. $A-C$, Averaged time courses of $\Delta[\mathrm{Hb} 0], \Delta[\mathrm{HbR}], \Delta[\mathrm{HbT}]$, and \% $\%$ cerebral blood flow from laser speckle-flow measurements from the contralateral hindpaw region of the somatosensory cortex of mice in P7-P8 $(\boldsymbol{A}), \mathrm{P} 10-\mathrm{P} 13(\boldsymbol{B})$, and adult $(\boldsymbol{C})$ age groups $(n=5,4,3$ respectively).
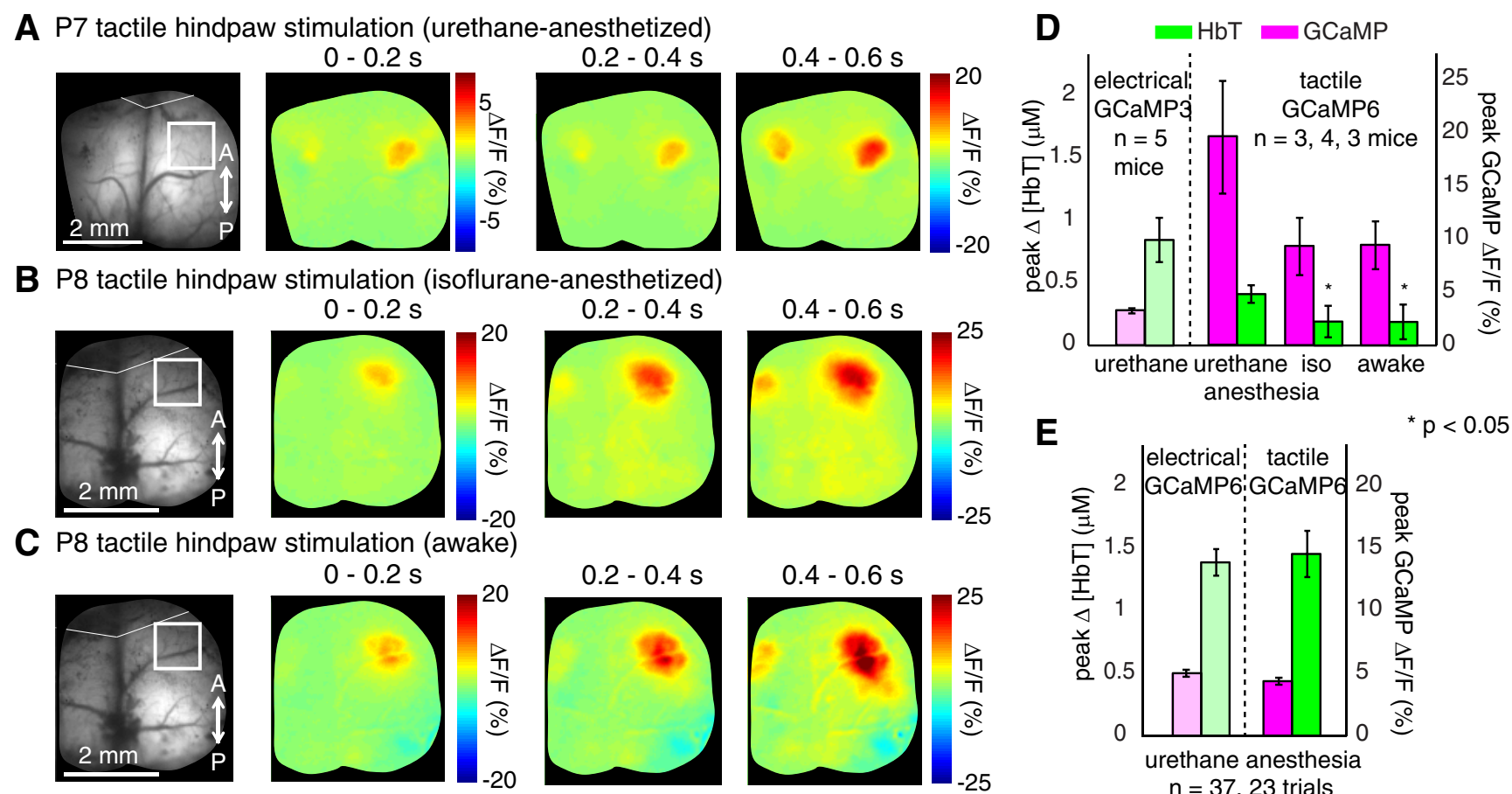

E

$$
{ }^{*} p<0.05
$$

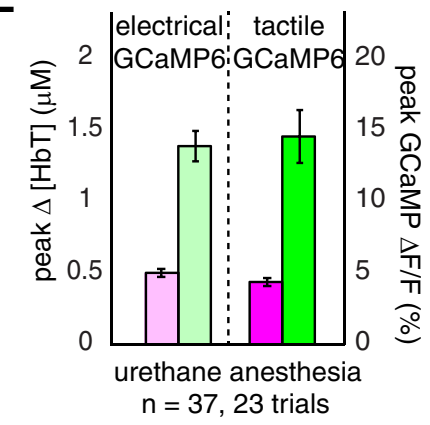

Figure 6. Awake and anesthetized postnatal mice exhibit robust neural responses to tactile hindpaw stimulus with minimal functional hyperemia. $\boldsymbol{A}-\boldsymbol{C}$, Left, Grayscale images of representative urethane-anesthetized, isoflurane-anesthetized, and awake mice. Bregma suture lines are marked with white lines. Right, GCaMP response maps for the same mice comparing the time period $0-0.2 \mathrm{~s}, 0.2-0.4 \mathrm{~s}$, and $0.4-0.6 \mathrm{~s}$ poststimulus onset to baseline ( $n=9,6,2$ trials respectively). Note: GCaMP6 mice were used for these experiments. D, Peak amplitude of GCaMP and $\Delta[H b T]$ responses ( $n=5,3,4,3$ mice respectively) in P7-P8 mice to electrical and tactile stimulus. Error bars show SEM; $p$ values use Student's $t$ test comparing HbT responses to electrical stimulation. Responses were extracted from the region of peak GCaMP response. $\boldsymbol{E}$, Comparison of peak amplitude of GCaMP and $\Delta[\mathrm{HbT}]$ responses in a single adult mouse to electrical and tactile stimuli.

mice were presented with stimuli lasting $2 \mathrm{~s}$, rather than $4 \mathrm{~s}$. The resulting adult GCaMP responses to a $2 \mathrm{~s}$ stimulus were confirmed to closely resemble the P7-P8 GCaMP response to $4 \mathrm{~s}$ stimuli. However, the peak amplitude of the adult $[\mathrm{HbT}]$ response to $2 \mathrm{~s}$ stimulus was found to be closer to the adult $4 \mathrm{~s}$ $[\mathrm{HbT}]$ response $(1.7 \pm 0.31$ and $1.9 \pm 0.37 \mu \mathrm{m}$ respectively) than to the much smaller $[\mathrm{HbT}]$ response in younger age groups (Fig. $4 G, H)$, confirming that shorter duration neural activity alone cannot account for the significantly lower-amplitude hemodynamic response observed in the younger age groups.

To confirm that the minimal hemodynamic responses observed in the younger age groups were not an artifact of optical intrinsic signal imaging, experiments were also performed using simultaneous laser speckle imaging of blood flow changes. As shown in Figure 5, consistent with $[\mathrm{HbT}]$ measurements, speckle-flow measurements confirm that younger age groups exhibit significantly smaller increases in stimulus-evoked cerebral blood flow than adult mice $(p<0.05)$. Similar time courses of speckle-flow contrast responses and $\Delta[\mathrm{HbT}]$ were confirmed across all three age groups (Fig. 5).

To confirm that the observed patterns of neural and hemodynamic responses were not a consequence of the chosen stimulus type, anesthesia, or GCaMP type, experiments were also repeated in P7-P8 and adult mice using tactile stimulation in which a single hindpaw was stimulated (using vibration). Mice were imaged under urethane anesthesia, under light isoflurane anesthesia $(1-2 \%)$, and while awake. Note that analysis of spontaneous activity is also presented below.

Figure $6 A-C$ shows time sequences of GCaMP response maps to tactile hindpaw stimulation from representative P7-P8 mice in urethane-anesthetized, isoflurane-anesthetized, and awake conditions. These GCaMP responses closely resemble those obtained with electrical hindpaw stimulation (Figs. 3, 4), being well localized to the contralateral hindpaw region and exhibiting minimal ipsilateral signal and intercortical spreading. Patterns were consistent under different anesthesia conditions and while awake, al- 

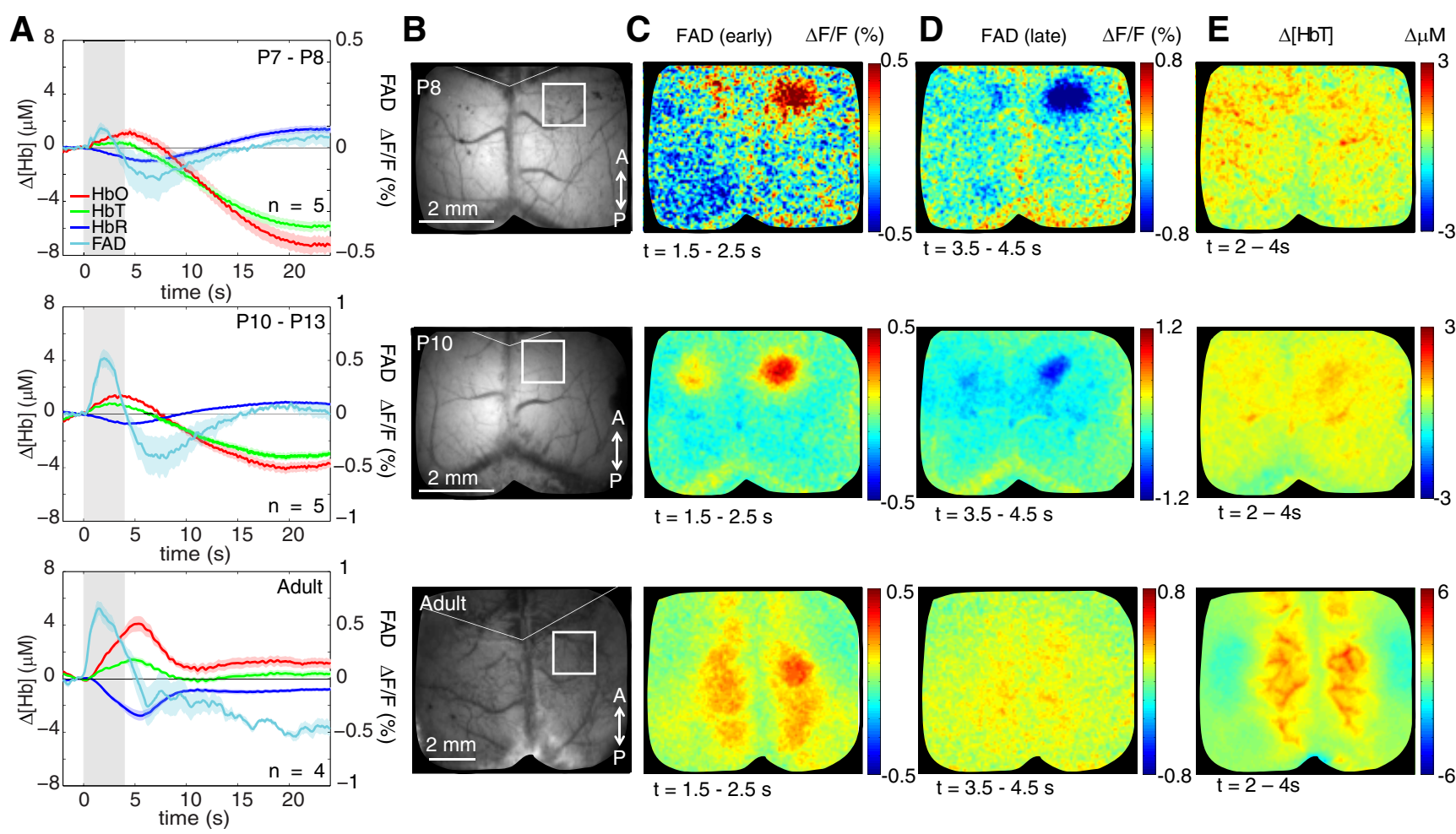

Figure 7. Age dependence of stimulus-evoked changes in oxidative metabolism. $\boldsymbol{A}$, Averaged hemodynamic and FAD response time courses in wild-type mice during unilateral hindpaw stimulation ( $n=5,6,6$ mice respectively), extracted from region of peak FAD response ( $\boldsymbol{B}$, white boxes). Error bounds show SEM. $\boldsymbol{B}$, Grayscale images of the cortex for a representative mouse from each age group. Bregma suture lines are marked with white lines. $\boldsymbol{C}, \boldsymbol{D}$, FAD functional response maps for the same mice comparing the time period $1.5-2.5$ ( $\boldsymbol{C}$; light phase) and 3.5-4.5 $\mathrm{s}$ poststimulus onset ( $\boldsymbol{D}$; dark phase) to baseline. $\boldsymbol{E}, \Delta[\mathrm{HbT}]$ functional map for the same mice comparing the time period $2-4 \mathrm{~s}$ poststimulus onset to baseline.

though, generally, responses under urethane anesthesia were slower than those obtained under isoflurane anesthesia and in awake conditions. The response maps shown in Figure $6 A-C$ were acquired in Thy1-GCaMP6 mice, demonstrating that mouse strain is also not a confounding factor in our observations (although yielding an expected higher amplitude $\Delta F / F$ across the groups; Fig. $6 D$ ). The spatiotemporal responses were confirmed to be similar across age groups in both Thy1-GCaMP6 and Thy1-GCaMP3 mice.

Figure $6 D, E$ shows analysis of GCaMP response amplitudes and concurrent hemodynamic responses across animals, stimulus conditions, and anesthesia states for P7-P8 and adult mice. These results confirm again that in the presence of robust neural responses, localized hemodynamic responses at P7-P8 are consistently much smaller than seen in the adult brain. Hemodynamic $(\Delta[\mathrm{HbT}])$ responses for tactile hindpaw stimulation across anesthesia states were even smaller in amplitude than hemodynamic responses to electrical hindpaw stimulation $(p<$ 0.05 ; Fig. $6 D)$. GCaMP peak response amplitudes $(\Delta F / F \%)$ were found to be highest under urethane anesthesia compared with light isoflurane and while awake, possibly due to increased levels of baseline activity in these more lightly anesthetized states (Fig. $6 D)$. There was no significant difference between GCaMP or $\Delta[\mathrm{HbT}]$ response amplitudes between tactile and electrical hindpaw stimulation in adult GCaMP6 animals (Fig. 6E).

\section{Mapping the metabolic consequences of neural activity in the} developing brain

The findings above provide a clear demonstration that, despite the presence of strong, localized neural activity in the early postnatal brain, this activity is not accompanied by the same localized increases in cortical blood flow that occur in the adult brain. This result raises the important question of how the developing brain meets its energy demands without activity-linked local functional hyperemia. Prior studies have suggested that the early postnatal brain performs primarily nonoxidative glucose metabolism (Booth et al., 1980; Bilger and Nehlig, 1991). So, to further explore the dynamics of oxygen consumption during brain development, stimulus-evoked FAD responses to stimulation were recorded to provide a direct measure of oxidative metabolism.

FAD is an intrinsically fluorescent coenzyme that is oxidized during oxidative phosphorylation and reduced to $\mathrm{FADH}_{2}$ by the tricarboxylic acid cycle (TCA cycle). FAD is more fluorescent than $\mathrm{FADH}_{2}$ and stimulus-evoked localized increases in cortical autofluorescence at $470 \mathrm{~nm}$ excitation have been rigorously demonstrated to correspond to an increased rate of oxidation of FAD, and thus an increase in oxidative metabolism (Shibuki et al., 2003). Here, FAD data were acquired in postnatal wild-type mice using identical preparation and stimulation paradigms as for GCaMP imaging (although weaker FAD fluorescence required $5 \times$ longer exposure times than for GCaMP3 recordings).

As shown in Figure 7C, well localized stimulus-evoked increases in FAD were observed in all three age groups. Moreover, the spatial patterns of FAD responses were found to be highly consistent with GCaMP responses: P7-P8 mice exhibit unilateral, localized increases in FAD, while P10-P13 mice have more bilateral responses, which are well localized to the hindpaw regions of the somatosensory cortex. Adult FAD increases are highest in the contralateral hindpaw region, but spread throughout the cortex.

Comparing the timing of FAD and GCaMP responses between cohorts, the onset and duration of both responses are closely aligned across the age groups (Fig. $8 A, B$ ), supporting previous reports that FAD fluorescence increases reflect primarily 
A

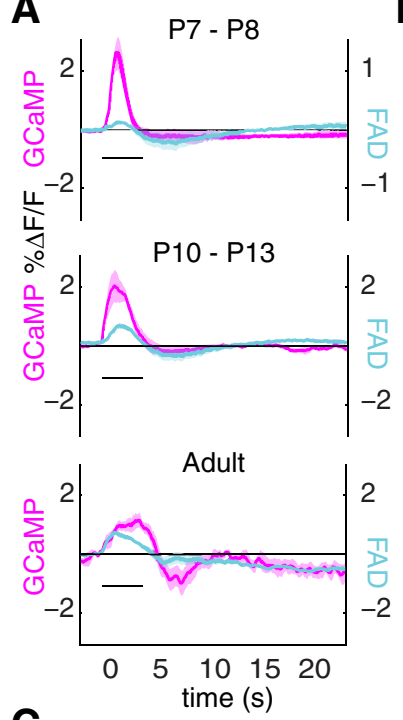

C

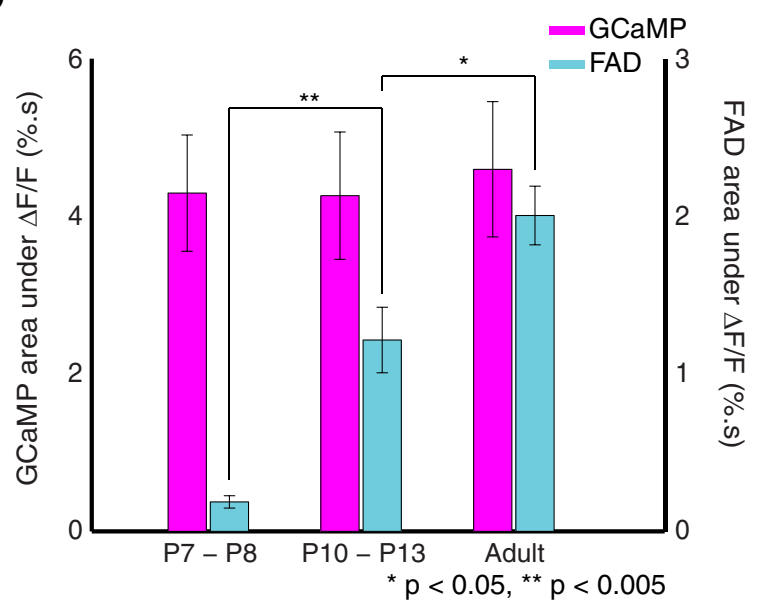

Figure 8. Quantitative comparison between neural and metabolic responses. $A$, Overlaid GCaMP and FAD time courses for each age group (different cohorts of mice). $\boldsymbol{B}$, Comparisons between the onset delay and duration timing of FAD compared with GCaMP responses for each age. Onset delay time was calculated as the time from the start of the stimulus $(0 \mathrm{~s})$ to the peak of the first derivative of the response. Response width was calculated as the full-width half maximum of the calcium or positive $F A D$ responses respectively. $C$, Area under the curve of FAD responses increases significantly with age $(p<0.005$ between P7-P8 and P10-P13 mice and $p<0.05$ between P10 $-\mathrm{P} 13$ and adult mice; Student's $t$ test), while the area under the curve of the GCaMP response is approximately constant with age. All error bars show SEM.

neural oxygen consumption (Shibuki et al., 2003; Reinert et al., 2011). A notable difference, however, is that the area under the curve of the GCaMP response remains constant while the FAD response increases significantly with age (Fig. $8 C$ ). This pattern suggests that some component of the activity in the immature brain is supported by nonoxidative metabolism, although the presence of measurable increases in FAD even at the youngest age groups suggests that functional hyperemia is not absent simply because oxygen is not required to support neural activity at this age.

In addition to the positive component of the FAD response, a delayed negative FAD "undershoot" is visible in the younger two age groups (Fig. 7A). Maps of the FAD response during this later "dark phase" demonstrate that the spatial localization of the overshoot and undershoot are very similar (Fig. 7C). Previous studies have observed similar "light" and "dark" phases of FAD fluorescence most commonly in in vitro brain-slice preparations
(Reinert et al., 2004; Kosterin et al., 2005). The light phase of FAD responses (increased fluorescence) is generally attributed to an increased rate of oxidative phosphorylation. The dark phase has been explained as an indication that FAD is being reduced to $\mathrm{FADH}_{2}$ by the TCA cycle at a faster rate than the oxidation of $\mathrm{FADH}_{2}$ to FAD by the electron transport chain (Reinert et al., 2011), a state that could occur due to a lack of available oxygen (Turner et al., 2007). The presence of a localized FAD dark phase immediately following the short-duration light phase in the younger age groups suggests a period of local oxygen depletion (Fig. 7A), such that the lack of functional hyperemia is not compensated for by another mechanism. The onset of this FAD dark phase and the timing of the early cessation of neural activity observed in the younger age groups (Fig. $8 A, B$ ) are also noted to be very similar.

In the in vivo adult brain, observed FAD dark phases have been challenging to distinguish from contamination of FAD fluorescence signals by hemoglobin absorption corresponding to accompanying functional hyperemia (Husson et al., 2007; Kitaura et al., 2007; Sirotin and Das, 2010). However, because little or no localized $[\mathrm{HbT}]$ increases are observed in the youngest two age groups in this data, hemodynamic contamination cannot be a confound here, and does not account for the spatially localized FAD undershoot observed. The hemodynamic correction applied to the FAD time courses (see Materials and Methods) did result in no dark phase being detected in the adult age group, as would be expected in the case where adequate hyperemia is meeting or exceeding the oxygen demands of the tissue. The slow downward trend seen in the adult response is not localized to the responding region and may correspond to photobleaching of FAD (Weber et al., 2004; Sirotin and Das, 2010).

\section{Evidence of oxygen consumption from hemoglobin oxygenation measurements}

The FAD results above suggest that oxygen consumption is occurring in the region of increased neural activity at P7-P8. To explore whether this consumption results in observable local decreases in oxygenation, we further examined the spatial and temporal components of the hemodynamic responses shown in Figures 4 and 7. We observed that the overall trend in [HbT] for the younger two age groups corresponds to a slight increase followed by a marked poststimulus decrease that is global (present throughout the bilateral imaging window) rather than localized. Prior studies have attributed such global hemodynamics in the brain to possible adrenergic effects, acting either within the brain (Bekar et al., 2012) or possibly via stimulus-evoked systemic blood pressure changes (Kozberg et al., 2013). This effect was less strongly observed, although still present, in animals undergoing tactile stimulus (Fig. 6).

Since these global changes overwhelm the hemodynamic recordings in the younger age groups, analysis was performed to subtract these components to permit closer examination of underlying hemodynamic and oximetric responses to stimulation. PCA was found to provide effective spatiotemporal separation of these global and local responses (see Materials and Methods). In all cases, the first principal component was found to temporally resemble the global hemodynamic response, as shown in Figure $9 A, C$, which closely resembles the raw hemodynamic data in Figure $4 A$. The spatial maps of this first component confirm a lack of functional localization, revealing only larger pial arteries and veins bilaterally. Subtracting these global first components yields the "residual" response shown in Figure $9 B, D$. In the P8 animal shown, 
A P8

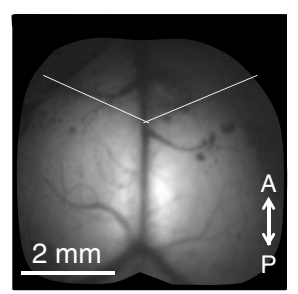

B

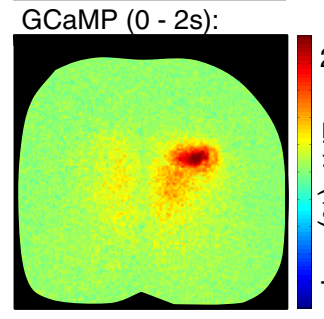

C P13

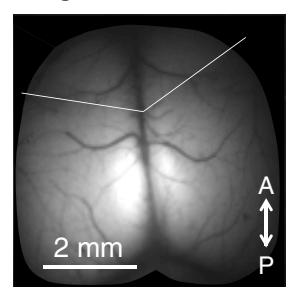

D $\operatorname{GCaMP}(0-2 \mathrm{~s})$ :

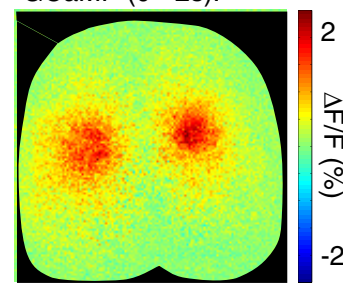

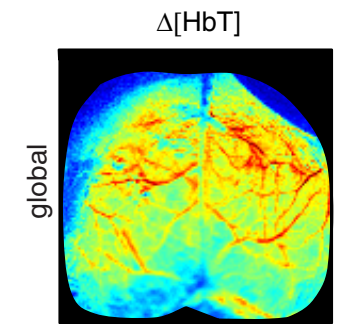

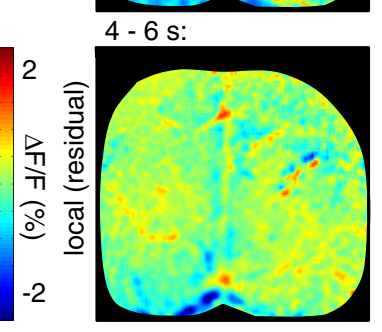

$\Delta[\mathrm{HbT}]$

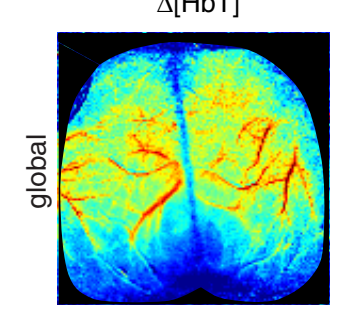

$$
4 \text { - } 6 \mathrm{s:}
$$
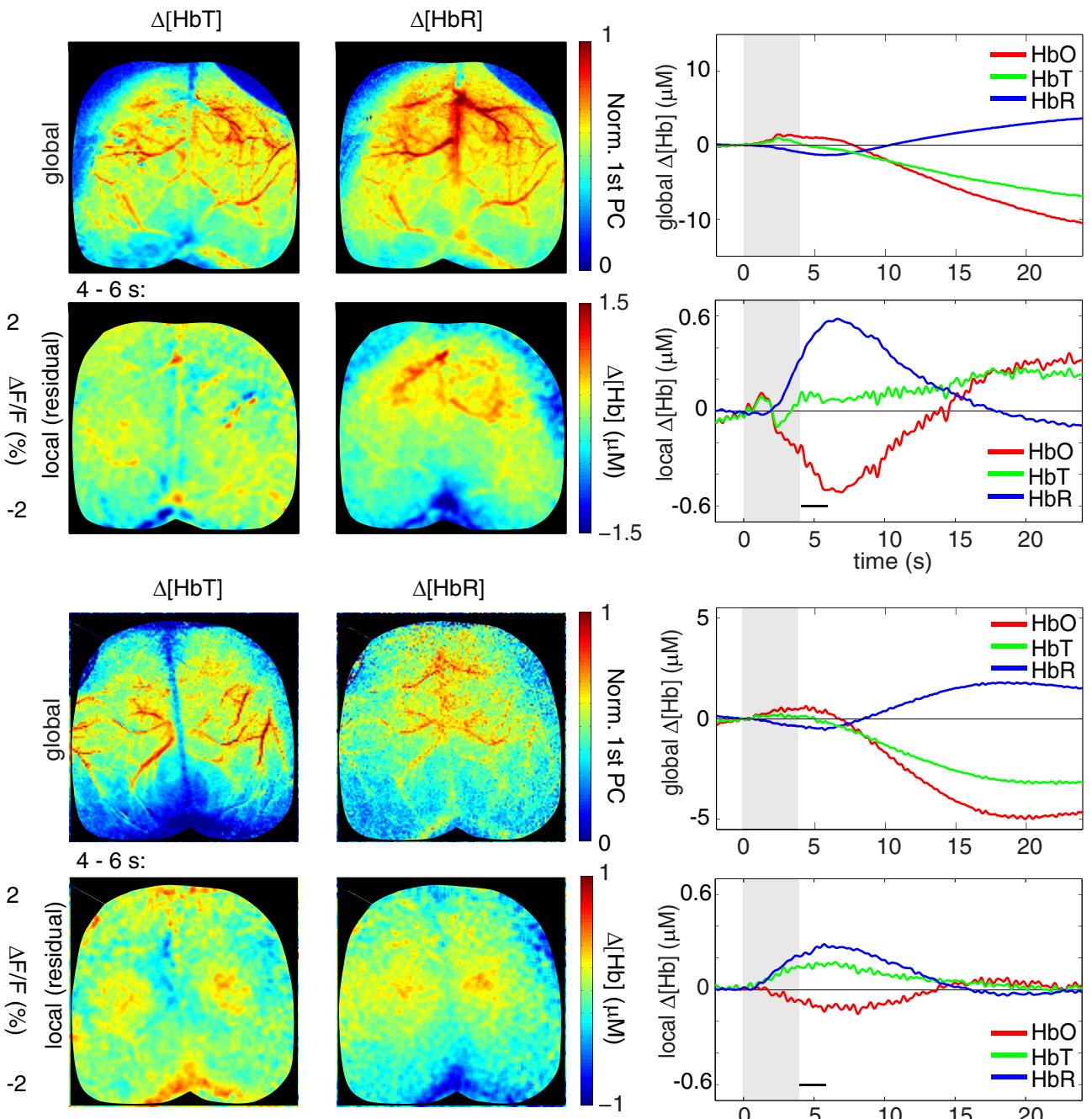
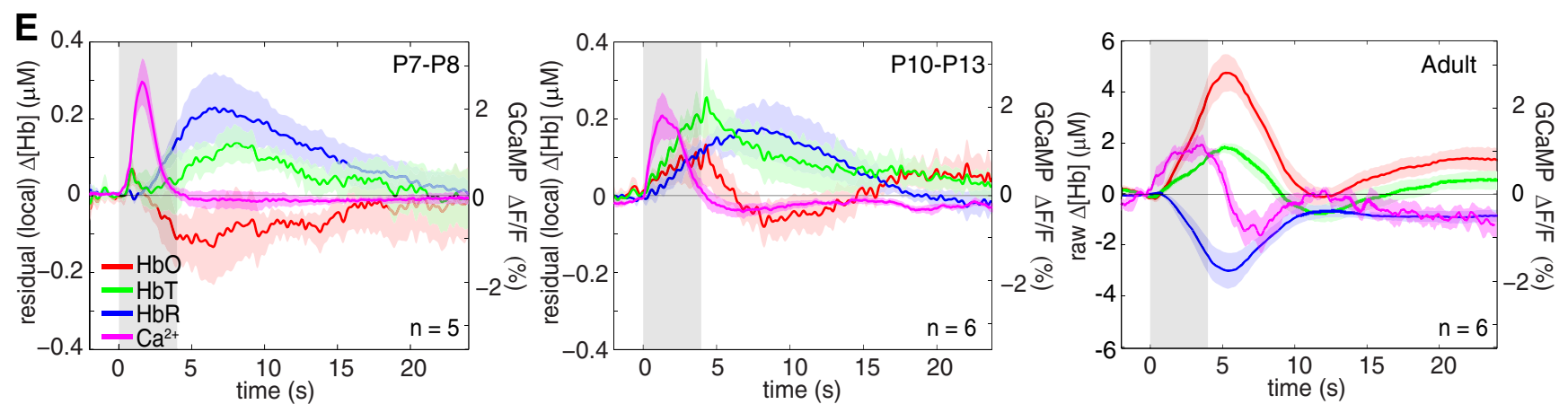

Figure 9. Subtraction of global signals reveals local oxygen consumption with minimal localized hyperemia. $\boldsymbol{A}$, P8 global response. Left, Grayscale image, Bregma suture lines are marked with white lines. Center, Maps of the global components of the $\Delta[\mathrm{HbT}]$ and $\Delta[\mathrm{HbR}]$ responses (score of the first principal component). Right, Time courses of the global components. $\boldsymbol{B}$, P8 local (residual) response. Left, GCaMP functional map for the time period $0-2$ s following stimulus onset. Center, Residual $\Delta[\mathrm{HbT}]$ and $\Delta[\mathrm{HbR}]$ functional maps after subtraction of the global component for the period $4-6$ s poststimulus onset. Right, Residual time courses of the response in regions which reached $\geq 50 \%$ of the maximum GCaMP response. $C, \boldsymbol{D}$, Same as $\boldsymbol{A}$ and $\boldsymbol{B}$ for a representative P13 mouse. $\boldsymbol{E}$, Average residual response time courses across animals after global subtraction for the younger two age groups with the GCaMP responses overlaid. Adult time courses are shown for reference (note the $15 \times$ expanded scale).

residual time courses extracted from the region exhibiting a GCaMP response confirm no underlying $[\mathrm{HbT}]$ increase. However, $[\mathrm{HbR}]$ is found to increase slightly as $[\mathrm{HbO}]$ decreases, a pattern consistent with oxygen extraction from the blood in the absence of functional hyperemia. The maps of this residual response also confirm no observable localized increase in $[\mathrm{HbT}]$, but show diffuse increases in $[\mathrm{HbR}]$ over the somatosensory cortex bilaterally. In maps of the residual responses in the P13 animal, localized, small increases in both $[\mathrm{HbT}]$ and $[\mathrm{HbR}]$ are observed in GCaMP-active regions. Residual time courses for these regions confirm small increases in $[\mathrm{HbT}]$, but also increases in [HbR] and slight decreases in $[\mathrm{HbO}]$, indicating functional hyperemia that is insufficient to fully balance the increase in oxygen consumption. 

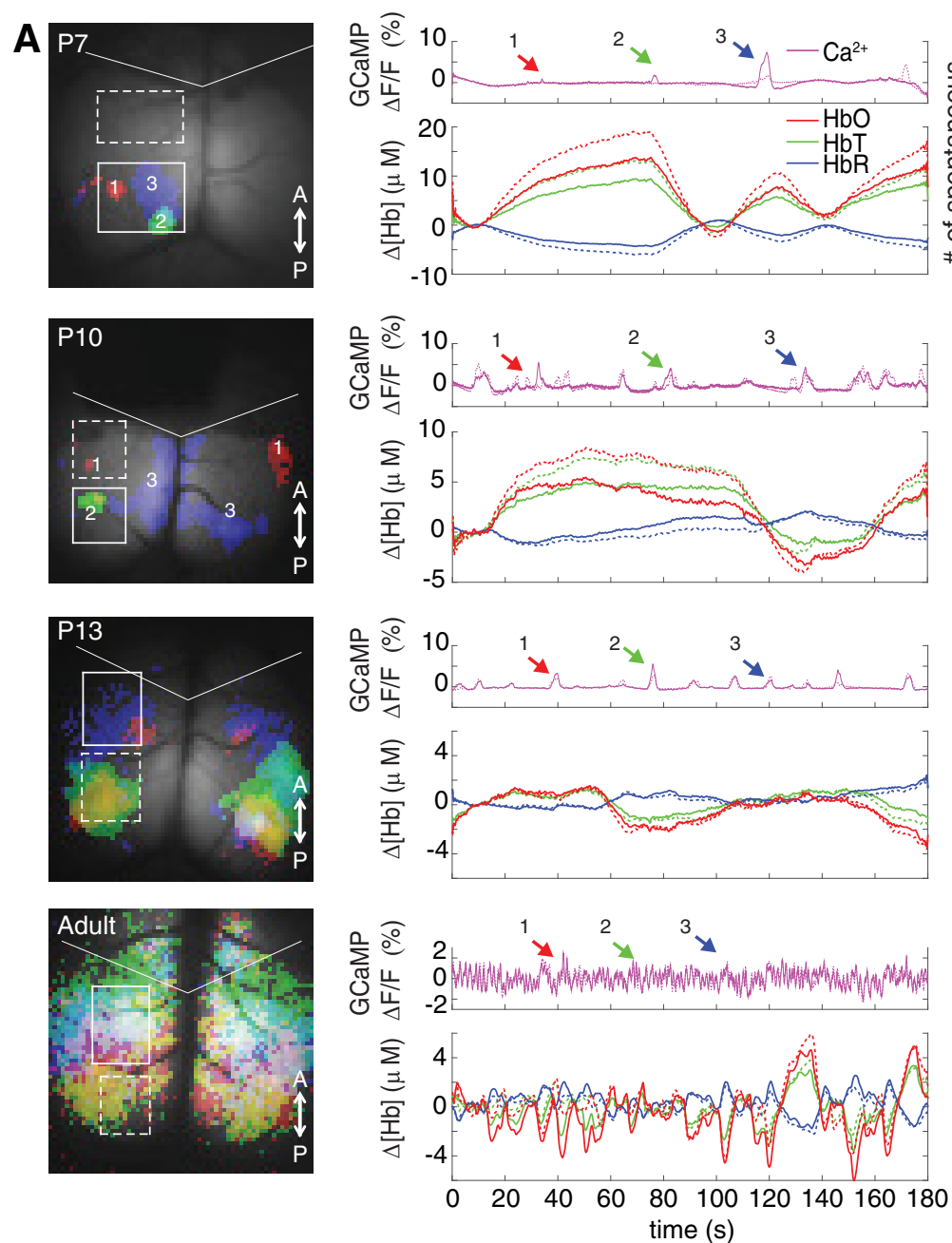
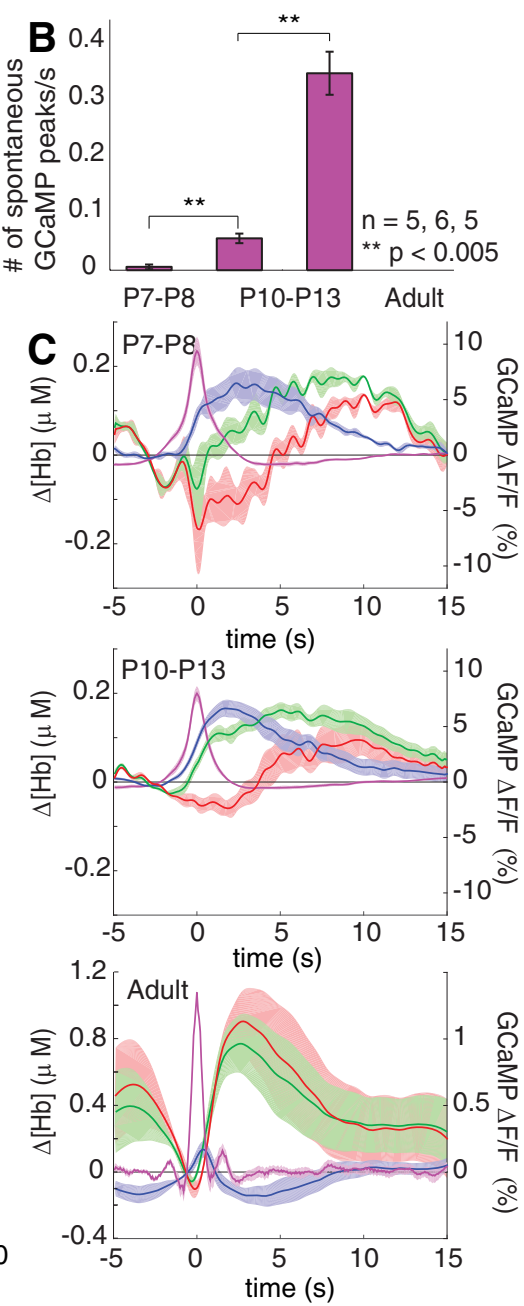

Figure 10. Spontaneous neural activity increases with age. $\boldsymbol{A}$, Right, Time courses of spontaneous (no stimulus) $\Delta[\mathrm{HbT}], \Delta[\mathrm{HbR}], \Delta[\mathrm{Hb} 0]$, and $\mathrm{GCaMP}$ activity over a 3 min period for four representative animals extracted from the regions indicated by white boxes at left as either solid or dashed lines respectively (mean values, low pass filtered at $3 \mathrm{~Hz}$ for hemodynamics, maximum values for GCaMP high pass filtered at $5 \mathrm{~Hz}$ ). Left, RGB merge maps ( $>50 \%$ peak) of three spontaneous GCaMP events (peaks indicated by arrow colors on the time course plots). The number and spatial spread of spontaneous events increases with age. Bregma suture lines are marked with white lines. $\boldsymbol{B}$, The number of spontaneous events per second averaged across all animals within each age group, demonstrating a significant increase in spontaneous activity with age ( $p<0.005$, Student's $t$ test, error bars show SEM). $\boldsymbol{C}$, Time courses of neural events and corresponding hemodynamic activity (P7-P8: $n=5$ mice, 15 trials, 161 events; P10 -P13: $n=6$ mice, 24 trials, 490 events; adult: $n=5$ mice, 28 trials, 934 events). Note that the nonzero pre-event baseline in adult hemodynamics reflects the high frequency of neighboring events.

Averaging across animals, the amplitude of residual [HbT] responses are found to increase with age, which is similar to what happens with the amplitude of uncorrected [HbT] responses (Fig. 4E,F). Averaged residual responses for the P7-P8 group show only a slight increase in $[\mathrm{HbT}]$, with a comparatively large increase in [HbR] and a decrease in [HbO] consistent with oxygen consumption (Fig. 9E). The temporal shape of these [HbR] increases corresponds well with previously reported cerebral metabolic rate of oxygen dynamics in adult animals (Vazquez et al., 2010). For the intermediate P10-P13 age group, a switching point can be seen in which hyperemia initially succeeds in increasing $[\mathrm{HbO}]$, but is ultimately overwhelmed by oxygen consumption. Although this analysis assumes that global and local hemodynamic effects combine linearly and are not interdependent, which is a simplification, these observations are consistent with immature neurovascular coupling providing insufficient functional hyperemia to exceed the oxygen consumption demands of the active region during early postnatal brain development.

\section{Spontaneous neural events also have minimal coupled hyperemia in the developing brain}

The results shown above focus on the evoked cortical response to external somatosensory stimulus. To assess coupling relationships in the resting state, GCaMP and hemodynamic data were also acquired in the absence of stimuli for continuous periods of $180 \mathrm{~s}$ in all GCaMP3 mice.

Analysis of this data revealed that spontaneous neural GCaMP events occur infrequently in the P7-P8 age group. Events that did occur were generally unilateral and rarely spread beyond their point of initiation, which is consistent with the patterns of stimulus-evoked responses observed in both GCaMP and FAD studies above (Fig. 10A,B). P10-P13 mice were found to exhibit significantly more frequent spontaneous neural events $(p<$ $0.005)$, with events spreading bilaterally and to wider cortical regions with increasing developmental age, again consistent with stimulus-evoked responses. Adult mice exhibited complex spontaneous neural activity, with most events appearing bilaterally and spreading rapidly throughout the cortex. 
Examining simultaneously acquired hemodynamics, large, slow fluctuations in $[\mathrm{HbT}],[\mathrm{HbO}]$, and $[\mathrm{HbR}]$ are observed across the cortex in both P7-P8 and P10-P13 mice (Fig. 10A). Plotting the time courses of neural and hemodynamic activity from two distinct cortical regions demonstrates that these large hemodynamic fluctuations are global and not coupled to local neural activity (Fig. 10A). Employing a similar method to analysis of stimulus-evoked responses above, subtraction of this global hemodynamic component using PCA (see Materials and Methods) was used to reveal underlying local hemodynamics. Residual hemodynamic responses were averaged over all spontaneous neural events as a function of age (Fig. 10C) using event-triggered averaging. Averaging reveals that the peak amplitude of individual spontaneous neural events decreases significantly with increasing age (Fig. 10C). However, similar to the findings with stimulus-evoked neural activity, increases in [HbT] corresponding to spontaneous neural events in the P7-P8 and P10-P13 age groups were found to be significantly smaller than the amplitudes of $[\mathrm{HbT}]$ increases triggered by spontaneous neural events in the adult brain $(p<0.05)$. As in the case of stimulus-evoked neural responses, spontaneous neural events in both of the younger age groups were found to drive local hypoxia, observed as small increases in deoxygenated hemoglobin.

The spatiotemporal similarities between spontaneous and evoked neural responses, and the lack of local hemodynamic coupling during spontaneous activity in the youngest age groups, rule out confounds related to stimulus-type or peripheral nervous system development in our stimulus-evoked response studies. These data demonstrate that, as with stimulus-evoked events, the energy needs of spontaneous events in early brain development are not met through tightly coupled functional hyperemia, which is consistent with the parallel postnatal development of neural and neurovascular networks.

\section{Discussion}

Despite the presence of localized neural activity, adult-like neurally coupled functional hyperemia was not observed during early postnatal brain development. Instead, hemodynamic responses were found to develop gradually, alongside the development of intrahemispheric and interhemispheric connectivity (Wang et al., 2007; Lewis et al., 2013). Measurements of local oxygen consumption confirmed that neural activity in the immature brain does use oxygen, and revealed a period of apparent oxygen insufficiency following neural events, likely resulting from the lack of evoked hyperemia. Analysis of hemoglobin oxygenation dynamics confirmed a dominating effect of oxygen consumption compared with functional hyperemia in the immature brain in both stimulus-evoked and resting-state conditions.

It is routinely assumed that neurovascular coupling is already in place at birth, and that functional hyperemia (and thus the fMRI positive BOLD signal) faithfully represents neural activity at any age. The results presented here demonstrate that despite the presence of neural activity and oxygen consumption, evoked blood flow increases are immature postnatally. We conclude that neural development and neurovascular development take place alongside one another in a metabolic environment that is markedly different from that of the adult brain.

\section{Why would neurovascular coupling develop postnatally?}

Significant angiogenesis as well as vascular pruning are known to occur postnatally (Norman, 1986). The cellular components of the neurovascular unit are also underdeveloped at birth (Harris et al., 2011). Astrocytes are known to be immature in the postnatal rat brain until P21 and do not reach adult density levels until P50 (Seregi et al., 1987; Stichel et al., 1991). Pericytes, which may contribute to adult neurovascular coupling (Hall et al., 2014), are also essential to angiogenesis, which could limit their role in early neurovascular regulation. Within the vascular endothelium, long-range hyperpolarization and short-range cyclooxygenase (COX) and nitric oxide (NO)-dependent pathways are all thought to contribute to functional hyperemia in the adult brain (Chen et al., 2014). However, postnatal increases in endothelial NO synthase expression have been reported (Bustamante et al., 2008), and pharmacological studies have demonstrated that dilations in the newborn brain are entirely mediated by COX pathways (Zuckerman et al., 1996). Thus, the machinery for connecting neural activity to local vessel dilations may simply not be in place during a time of extensive vascular development and remodeling.

The concurrent development of neural and vascular circuitry may also serve to gradually establish an optimized system for blood delivery in the mature brain. Several recent studies have suggested that neural activity during early brain development influences the eventual density of cortical microvasculature (Lacoste et al., 2014; Whiteus et al., 2014). The FAD results presented above demonstrate that the absence of functional hyperemia in the neonatal brain leads to locally depleted oxygen in the responding region. This observation could provide a possible mechanism for activity-linked angiogenesis, driven by the sequential neurally evoked localized hypoxic events observed here (Shweiki et al., 1992; Pugh and Ratcliffe, 2003). Equally, the lack of hyperemia to replenish supplies of both oxygen and glucose in the immature brain could impose an energetic limit on sustained neural activity; consistent with the similarities in timing between the early cessation of neural activity in younger animals and the onset of the dark phase of the FAD response. Decreases in neural excitability after firing have been noted by others in the neonatal brain (Zehendner et al., 2013), which is consistent with our observation of shortened neural responses and sparse spontaneous events in the immature brain.

Understanding how these metabolic conditions influence and shape postnatal brain development could have important implications for the care of preterm infants and in understanding the pathophysiology of developmental disorders. For example, the possible role of oxygen depletions in guiding vascular development may be relevant to the counterintuitive effects of oxygen supplementation in premature infants and newborns. The development of aberrant retinal vasculature in premature infants given excessive oxygen is well documented. Resuscitation of infants with room air has also been shown to offer better clinical outcomes and less brain damage than using 100\% oxygen (Saugstad, 2010). A better understanding of neurovascular development and the consequently unusual metabolic state of the developing brain could provide new therapeutic targets and diagnostic strategies for brain disorders emerging during gestation, infancy, and early childhood.

\section{Implications for functional imaging of the neonatal brain}

Almost all human functional brain imaging technologies, including fMRI and near infrared spectroscopy (NIRS), rely on measuring changes in hemodynamics to report underlying neural activity. While the results presented here were obtained in mice, many prior studies in humans have observed anomalous patterns of hemodynamic responses in human infants and children, including a recent study that showed a biphasic BOLD response in term newborn humans (Arichi et al., 2012) similar to the [HbR] responses in $\mathrm{P} 10-\mathrm{P} 13$ mice shown in Figure $4 A$. It is important to 
note that it has yet to be established how the time periods of brain development observed here in mice [and previously in rats (Kozberg et al., 2013)] map onto human brain development. It is possible that the "neurovascular age" of a P7-P8 mouse is equivalent to a period of fetal development (or a premature infant), rather than a term human newborn. However, the clear observations of inverted and anomalous fMRI responses in human infants and children suggest that aspects of neurovascular development remain incomplete in the human newborn, and could continue during early childhood in parallel with ongoing expansion of neural networks and cognitive development. Given these considerations, the points below summarize the implications of our results for interpretation of fMRI data in the developing brain.

First, newborns may be especially susceptible to systemic hemodynamic responses to stimulus, which can be reflected in global changes in cerebral blood flow, possibly because of immature autoregulation (Kozberg et al., 2013). Global increases in cerebral blood flow could be inadvertently interpreted as spatially distributed, positive (adult-like) responses, suggesting a large and diffuse spatial extent of underlying neural activity, whereas our GCaMP data confirm the opposite, that cortical neural responses are tightly localized before the postnatal expansion of neural connectivity.

Second, in experimental paradigms in which global hemodynamic effects can be eliminated or removed (Fig. 9), our results suggest that the youngest subjects may exhibit small, wholly negative BOLD responses, representing deoxygenation due to local oxygen consumption. We note that such responses were reported in some of the earliest fMRI studies of the newborn human brain (Born et al., 1996; Anderson et al., 2001).

Third, as hyperemia begins to develop, negative BOLD responses representing oxygen consumption may still be evident, although gradually countered by developing hyperemia. In some cases, there could be no BOLD change at all if supply exactly matches demand, while in others, biphasic patterns may occur. An accurate knowledge of an age-appropriate "hemodynamic response function" may thus be required to draw conclusions about the timing and spatial extent of neural activity (Colonnese et al., 2008; Arichi et al., 2012).

Fourth, because negative BOLD responses generally reflect oxygen consumption, while positive BOLD responses are driven by functional hyperemia, the two may not be spatially equivalent. Our GCaMP and FAD results further suggest that neither positive nor negative BOLD responses can be expected to map exactly to underlying neural activity.

Fifth, the patterns of spontaneous neural activity and hemodynamics demonstrated in the developing brain have important implications for resting-state functional-connectivity fMRI studies. Resting-state fMRI is increasingly being used for studies of human brain development, in part because the technique does not require training in a task and can be used to scan infants while they sleep. Although relatively symmetric and recognizable functional connectivity maps have been reported in very young infants (Doria et al., 2010), our results suggest that different factors could be governing the modulation of blood flow in the immature brain, compared with the adult brain (Fig. 10). Large-scale, globally correlated fluctuations in hemodynamics were observed in the immature mouse brain, but were found to be uncoupled to spontaneous neural activity. Thus, symmetric resting-state networks derived from these large hemodynamic trends would not reflect neural network development, whereas true network development would be encoded in much smaller deoxygenations that would manifest as rare negative BOLD events, and could be expected to reveal limited or unilateral networks in the very immature brain.

Although our results challenge conventional interpretation of fMRI data acquired during early brain development, fMRI (and NIRS) might be ideal techniques for capturing the hallmarks of postnatal neurovascular development. The large resting-state fluctuations in hemodynamics observed here, for example, are likely an important component of brain development, and may serve to provide adequate modulation of blood flow before the mechanisms for local coupling of blood flow to neural activity are in place. Apparent changes in functional connectivity in infants and children with developmental disorders could thus feasibly reflect abnormal development of the brain's energetic infrastructure, rather than abnormalities in neural connectivity. Functional brain-imaging modalities are therefore ideally placed to reveal valuable new biomarkers for normal and abnormal developmental trajectories, and to provide new opportunities for developing diagnostic tools and therapies targeting neurovascular dysfunction (Hillman and Kozberg, 2013). Our results both provide a roadmap for exploration of these new biomarkers, and suggest mechanistic links between normal neurovascular development and the healthy development of the human brain.

\section{References}

Anderson AW, Marois R, Colson ER, Peterson BS, Duncan CC, Ehrenkranz RA, Schneider KC, Gore JC, Ment LR (2001) Neonatal auditory activation detected by functional magnetic resonance imaging. Magn Reson Imaging 19:1-5. CrossRef Medline

Arichi T, Fagiolo G, Varela M, Melendez-Calderon A, Allievi A, Merchant N, Tusor N, Counsell SJ, Burdet E, Beckmann CF, Edwards AD (2012) Development of BOLD signal hemodynamic responses in the human brain. Neuroimage 63:663-673. CrossRef Medline

Bekar LK, Wei HS, Nedergaard M (2012) The locus ceruleus-norepinephrine network optimizes coupling of cerebral blood volume with oxygen demand. J Cereb Blood Flow Metab 32:2135-2145. CrossRef Medline

Bilger A, Nehlig A (1991) Quantitative histochemical changes in enzymes involved in energy metabolism in the rat brain during postnatal development. I. Cytochrome oxidase and lactate dehydrogenase. Int J Dev Neurosci 9:545-553. CrossRef Medline

Boas DA, Dunn AK (2010) Laser speckle contrast imaging in biomedical optics. J Biomed Opt 15:011109. CrossRef Medline

Booth RF, Patel TB, Clark JB (1980) The development of enzymes of energy metabolism in the brain of a precocial (guinea pig) and nonprecocial (rat) species. J Neurochem 34:17-25. CrossRef Medline

Born P, Rostrup E, Leth H, Peitersen B, Lou HC (1996) Change of visually induced cortical activation patterns during development. Lancet 347:543. CrossRef Medline

Bouchard MB, Chen BR, Burgess SA, Hillman EM (2009) Ultra-fast multispectral optical imaging of cortical oxygenation, blood flow, and intracellular calcium dynamics. Opt Express 17:15670-15678. CrossRef Medline

Bustamante J, Czerniczyniec A, Cymeryng C, Lores-Arnaiz S (2008) Age related changes from youth to adulthood in rat brain cortex: nitric oxide synthase and mitochondrial respiratory function. Neurochem Res 33: 1216-1223. CrossRef Medline

Chen BR, Bouchard MB, McCaslin AF, Burgess SA, Hillman EM (2011) High-speed vascular dynamics of the hemodynamic response. Neuroimage 54:1021-1030. CrossRef Medline

Chen BR, Kozberg MG, Bouchard MB, Shaik MA, Hillman EMC (2014) A critical role for the vascular endothelium in functional neurovascular coupling in the brain. J Am Hear Assoc 3:e000787. CrossRef Medline

Cohen-Cory S (2002) The developing synapse: construction and modulation of synaptic structures and circuits. Science 298:770-776. CrossRef Medline

Colonnese MT, Phillips MA, Constantine-Paton M, Kaila K, Jasanoff A (2008) Development of hemodynamic responses and functional connectivity in rat somatosensory cortex. Nat Neurosci 11:72-79. CrossRef Medline 
Doria V, Beckmann CF, Arichi T, Merchant N, Groppo M, Turkheimer FE, Counsell SJ, Murgasova M, Aljabar P, Nunes RG, Larkman DJ, Rees G, Edwards AD (2010) Emergence of resting state networks in the preterm human brain. Proc Natl Acad Sci U S A 107:20015-20020. CrossRef Medline

Ferezou I, Haiss F, Gentet LJ, Aronoff R, Weber B, Petersen CC (2007) Spatiotemporal dynamics of cortical sensorimotor integration in behaving mice. Neuron 56:907-923. CrossRef Medline

Hall CN, Reynell C, Gesslein B, Hamilton NB, Mishra A, Sutherland BA, O'Farrell FM, Buchan AM, Lauritzen M, Attwell D (2014) Capillary pericytes regulate cerebral blood flow in health and disease. Nature 508: 55-60. CrossRef Medline

Harris JJ, Reynell C, Attwell D (2011) The physiology of developmental changes in BOLD functional imaging signals. Dev Cogn Neurosci 1: 199-216. CrossRef Medline

Heeger DJ, Ress D (2002) What does fMRI tell us about neuronal activity? Nat Rev Neurosci 3:142-151. CrossRef Medline

Hillman EM (2014) Coupling mechanism and significance of the BOLD signal: a status report. Annu Rev Neurosci 37:161-181. CrossRef Medline

Hillman EM, Kozberg MG (2013) What secrets can functional MRI reveal about the developing infant brain? Imaging Med 5:203-206. CrossRef

Hillman EM, Devor A, Bouchard MB, Dunn AK, Krauss GW, Skoch J, Bacskai BJ, Dale AM, Boas DA (2007) Depth-resolved optical imaging and microscopy of vascular compartment dynamics during somatosensory stimulation. Neuroimage 35:89-104. CrossRef Medline

Husson TR, Mallik AK, Zhang JX, Issa NP (2007) Functional imaging of primary visual cortex using flavoprotein autofluorescence. J Neurosci 27:8665-8675. CrossRef Medline

Huttenlocher PR, de Courten C, Garey LJ, Van der Loos H (1982) Synaptogenesis in human visual cortex - evidence for synapse elimination during normal development. Neurosci Lett 33:247-252. CrossRef Medline

Kitaura H, Uozumi N, Tohmi M, Yamazaki M, Sakimura K, Kudoh M, Shimizu T, Shibuki K (2007) Roles of nitric oxide as a vasodilator in neurovascular coupling of mouse somatosensory cortex. Neurosci Res 59: 160-171. CrossRef Medline

Kosterin P, Kim GH, Muschol M, Obaid AL, Salzberg BM (2005) Changes in $\mathrm{FAD}$ and $\mathrm{NADH}$ fluorescence in neurosecretory terminals are triggered by calcium entry and by ADP production. J Membr Biol 208:113-124. CrossRef Medline

Kozberg MG, Chen BR, DeLeo SE, Bouchard MB, Hillman EM (2013) Resolving the transition from negative to positive blood oxygen leveldependent responses in the developing brain. Proc Natl Acad Sci U S A 110:4380-4385. CrossRef Medline

Lacoste B, Comin CH, Ben-Zvi A, Kaeser PS, Xu X, Costa Lda F, Gu C (2014) Sensory-related neural activity regulates the structure of vascular networks in the cerebral cortex. Neuron 83:1117-1130. CrossRef Medline

Lewis TL Jr, Courchet J, Polleux F (2013) Cell biology in neuroscience: cellular and molecular mechanisms underlying axon formation, growth, and branching. J Cell Biol 202:837-848. CrossRef Medline

Logothetis NK, Pauls J, Augath M, Trinath T, Oeltermann A (2001) Neurophysiological investigation of the basis of the fMRI signal. Nature 412: 150-157. CrossRef Medline

Mall V, Linder M, Herpers M, Schelle A, Mendez-Mendez J, Korinthenberg R, Schumacher M, Spreer J (2005) Recruitment of the sensorimotor cortex-a developmental FMRI study. Neuropediatrics 36:373-379. CrossRef Medline

Marcano-Reik AJ, Blumberg MS (2008) The corpus callosum modulates spindle-burst activity within homotopic regions of somatosensory cortex in newborn rats. Eur J Neurosci 28:1457-1466. CrossRef Medline

McVea DA, Mohajerani MH, Murphy TH (2012) Voltage-sensitive dye imaging reveals dynamic spatiotemporal properties of cortical activity after spontaneous muscle twitches in the newborn rat. J Neurosci 32:1098210994. CrossRef Medline

Meek JH, Firbank M, Elwell CE, Atkinson J, Braddick O, Wyatt JS (1998) Regional hemodynamic responses to visual stimulation in awake infants. Pediatr Res 43:840-843. CrossRef Medline
Mohajerani MH, McVea DA, Fingas M, Murphy TH (2010) Mirrored bilateral slow-wave cortical activity within local circuits revealed by fast bihemispheric voltage-sensitive dye imaging in anesthetized and awake mice. J Neurosci 30:3745-3751. CrossRef Medline

Norman MG, O'Kusky JR (1986) The growth and development of microvasculature in human cerebral cortex. J Neuropathol Exp Neurol 45: 222-232. Medline

Pugh CW, Ratcliffe PJ (2003) Regulation of angiogenesis by hypoxia: role of the HIF system. Nat Med 9:677-684. CrossRef Medline

Quairiaux C, Mégevand P, Kiss JZ, Michel CM (2011) Functional development of large-scale sensorimotor cortical networks in the brain. J Neurosci 31:9574-9584. CrossRef Medline

Reinert KC, Dunbar RL, Gao W, Chen G, Ebner TJ (2004) Flavoprotein autofluorescence imaging of neuronal activation in the cerebellar cortex in vivo. J Neurophysiol 92:199-211. CrossRef Medline

Reinert KC, Gao W, Chen G, Wang X, Peng YP, Ebner TJ (2011) Cellular and metabolic origins of flavoprotein autofluorescence in the cerebellar cortex in vivo. Cerebellum 10:585-599. CrossRef Medline

Sakaguchi K, Tachibana T, Furukawa S, Katsura T, Yamazaki K, Kawaguchi H, Maki A, Okada E (2007) Experimental prediction of the wavelengthdependent path-length factor for optical intrinsic signal analysis. Appl Opt 46:2769-2777. CrossRef Medline

Saugstad OD (2010) Resuscitation of newborn infants: from oxygen to room air. Lancet 376:1970-1971. CrossRef Medline

Seregi A, Keller M, Hertting G (1987) Are cerebral prostanoids of astroglial origin? Studies on the prostanoid forming system in developing rat brain and primary cultures of rat astrocytes. Brain Res 404:113-120. CrossRef Medline

Shibuki K, Hishida R, Murakami H, Kudoh M, Kawaguchi T, Watanabe M, Watanabe S, Kouuchi T, Tanaka R (2003) Dynamic imaging of somatosensory cortical activity in the rat visualized by flavoprotein autofluorescence. J Physiol 549:919-927. CrossRef Medline

Shweiki D, Itin A, Soffer D, Keshet E (1992) Vascular endothelial growth factor induced by hypoxia may mediate hypoxia-initiated angiogenesis. Nature 359:843-845. CrossRef Medline

Sirotin YB, Das A (2010) Spatial relationship between flavoprotein fluorescence and the hemodynamic response in the primary visual cortex of alert macaque monkeys. Front Neuroenergetics 2:6. CrossRef Medline

Stichel CC, Müller CM, Zilles K (1991) Distribution of glial fibrillary acidic protein and vimentin immunoreactivity during rat visual cortex development. J Neurocytol 20:97-108. CrossRef Medline

Turner DA, Foster KA, Galeffi F, Somjen GG (2007) Differences in O2 availability resolve the apparent discrepancies in metabolic intrinsic optical signals in vivo and in vitro. Trends Neurosci 30:390-398. CrossRef Medline

Vazquez AL, Masamoto K, Fukuda M, Kim SG (2010) Cerebral oxygen delivery and consumption during evoked neural activity. Front Neuroenergetics 2:11. CrossRef Medline

Wang CL, Zhang L, Zhou Y, Zhou J, Yang XJ, Duan S, Xiong ZQ, Ding YQ (2007) Activity-dependent development of callosal projections in the somatosensory cortex. J Neurosci 27:11334-11342. CrossRef Medline

Weber B, Burger C, Wyss MT, von Schulthess GK, Scheffold F, Buck A (2004) Optical imaging of the spatiotemporal dynamics of cerebral blood flow and oxidative metabolism in the rat barrel cortex. Eur J Neurosci 20:2664-2670. CrossRef Medline

Whiteus C, Freitas C, Grutzendler J (2014) Perturbed neural activity disrupts cerebral angiogenesis during a postnatal critical period. Nature 505: 407-411. CrossRef Medline

Zehendner CM, Tsohataridis S, Luhmann HJ, Yang JW (2013) Developmental switch in neurovascular coupling in the immature rodent barrel cortex. PLoS One 8:e80749. CrossRef Medline

Zuckerman SL, Armstead WM, Hsu P, Shibata M, Leffler CW (1996) Age dependence of cerebrovascular response mechanisms in domestic pigs. Am J Physiol 271:H535-H540. Medline 